\title{
Macronutrient Modifications of Optimal Foraging Theory: An Approach Using Indifference Curves Applied to Some Modern Foragers
}

\author{
Kim Hill ${ }^{1}$
}

The use of energy (calories) as the currency to be maximized per unit time in Optimal Foraging Models is considered in light of data on several foraging groups. Observations on the Ache, Cuiva, and Yora foragers suggest men do not attempt to maximize energetic return rates, but instead often concentrate on acquiring meat resources which provide lower energetic returns. The possibility that this preference is due to the macronutrient composition of hunted and gathered foods is explored. Indifference curves are introduced as a means of modeling the tradeoff between two desirable commodities, meat (protein-lipid) and carbohydrate, and a specific indifference curve is derived using observed choices in five foraging situatiuons. This curve is used to predict the amount o meat that Mbuti foragers will trade for carbohydrate, in an attempt to test the utility of the approach.

KEY WORDS: nutrients; foraging theory; hunter-gatherers; South America.

\section{INTRODUCTION}

Models derived from Optimal Foraging Theory (OFT) have been increasingly employed in recent years in an attempt to predict and explain human diet and subsistence strategies, especially among modern huntergatherers (Smith, 1983; Winterhalder and Smith, 1981). Typically, models address questions of diet breadth (Hames and Vickers 1982; Hawkes Hill, and O'Connell, 1982; Hill and Hawkes, 1983; Hill, Kaplan, Hawkes,

'Department of Anthropology, Emory University, Atlanta, Georgia 30322.

${ }^{3}$ Current address: Department of Anthropology, University of Michigan, Ann Arbor, Michigan 48109 . 
and Hurtado, 1987; O'Connell and Hawkes, 1981; Winterhalder, 1977, 1981), foraging group size (Smith, 1981, 1985), resource patch choice (O'Connell and Hawkes, 1981), and amount of time allocated to different foraging activities (Beckerman, 1983; Smith, 1980). These "first generation" models are all based on a variety of simplifying assumptions. For example, the optimal diet model (Charnov and Orians, 1973; MacArthur and Pianka, 1966) assumes: (1) prey items are randomly or uniformly distributed and encountered at a constant rate, (2) time spent in pursuit or handling of a resource is exclusive of time spent searching for, pursuing, or processing other resources, and (3) the forager has perfect knowledge of the densities of various prey types and the time on average necessary to handle each one. The simples OFT models also generally assume that foragers behave in such a way as to maximize their net energy (caloric) acquisition rate.

In recent years, "first generation" OFT models have been modified considerably to make them more biologically realistic, and to incorporate situations that are known or suspected to violate the original simplifying assumptions (see Stephens and Krebs, 1986, for a review). This trend has now also become apparent in applications of OFT to human subsistence problems. For example, in the face of stochastic rather than deterministic resource encounter rates and handling times, several authors have discussed how the avoidance of a critical food shortfall (risk) could modify subsistence strategies and affect food redistribution patterns (Hill et al., 1987; Kaplan and Hill, 1985a; Smith, 1987; Winterhalder, 1987). Other modifications consider patchiness due to spatial distribution (O'Connell and Hawkes, 1981), or tool availability (Hawkes et al., 1982), and the assessment of the conditions under which high levels of knowledge about foraging options outweigh the costs of acquiring that knowledge (see Boyd and Richerson, 1985, for a general discussion). Even methods for adjusting diet breadth models to take into account overlap in pursuit or processing of multiple resources, or the observation that processing time does not compete with foraging time have been suggested (Hill et al., 1987).

All of these modifications, however, have continued to incorporate the assumption that the benefits derived from alternative acquisition strategies can be usefully measured in energetic terms. The adherence to enegy-based models seems primarily due to two factors. First, energy-based models have continued to dominate foraging studies of non-human organisms. In fact, the reduction of benefits to an energy-based currency has probably been partially responsible for the choice of most experimental animal systems for testing OFT (Rapport, 1980), and the notable avoidance of others, particularly omnivores. Considerations of the possible effects of nutrient constraints or complementarity on nonhuman foraging behavior have been few (for some exceptions see Altman and Wagner, 1978; Belovsky, 1978, 1984; Covich, 1972; Milton, 1979; Pulliam, 1975; Pyke, Pulliam, and Charnov, 1977; 
Rapport, 1971, 1980). Second, the desire to keep models simple and to avoid incorporating multiple poorly understood (or poorly justified) nutrient constraints has been partially responsible for the adherence to energy-based models of human foraging (Hawkes, O'Connell, and Charnov, 1985; Hawkes and O'Connell, 1985). Earlier linear programming models which did consider nutrients other than energy (see Reidhead, 1979, for review) seemed both very complex and incomplete, as more required nutrients were added and discovered, or recommended minimum daily requirements changed (Keene, 1981, p. 187).

Although they have continued to adhere to energy-based foraging models, most researchers using OFT to predict human subsistence strategies are probably somewhat uncomfortable with the assumption that all food resources are perfectly substitutable calorie for calorie. This has been a major point for attack by critics of OFT (Keene, 1981; Sih and Milton, 1985), and even proponents such as Smith (1983) readily acknowledge that this is an area where foraging models are likely to need some modifications. One of the problems confronting those who wish to model human subsistence and incorporate biologically realistic assumptions about nutrients has been a lack of solid information on the importance and relative value of different nutrients to humans. Linear programming and other nutrient constraints models assume from the outset that energy rate maximization (or risk minimization) alone is not the only subsistence goal. They also assume that human foraging decisions are motivated by the need to meet currently recognized (by whatever study they cite) minimum daily requirements for specific nutrients. This assumption seems to rest on a further assumption that the biological value of differing amounts of each nutrient is characterized by a step function. When an insufficient amount of a specific nutrient has been acquired, there are no biological benefits to be derived (death results), but once the required minimum is met, no additional biological benefits can be derived from greater intake levels of the nutrient in question. Hawkes (1987) has criticized this assumption because it is based upon the premise of "limited" nutritional needs for which there is little theoretical or empirical support.

Currently, there exist very few studies in humans concerning the biological effects of differing nutrient intake levels above the minimum recommended daily requirements. The casual observation that most human groups seem strongly motivated to consume more than the minimum daily requirement for many nutrients suggests those requirements are not goals. In addition, the minimum requirements themselves seem difficult if not impossible to determine due to their apparent condition-specific nature, and the level of gross pathology chosen to define them (Durnin, Edholm, Miller, and Waterlow, 1973). Because of this, the linear programming approach, which assumes foragers will maximize energy (or protein) acquisition rates subject to specified nutrient constraints, seems unlikely to provide a straightforward 
solution to the question of diet composition. Nevertheless, two key questions remain: (1) are energy maximizing models grossly inaccurate in predicting human foraging decisions? and (2) if so, how can they be modified to be more useful, without totally abandoning what appears to be a productive approach to studying human foraging behavior?

The goals of this paper are three: (1) to present some quantitative data suggesting that modifications of simple OFT models are necessary in order to account for observed foraging decisions, (2) to introduce an approach that may be helpful for incorporating macronutrient considerations into foraging models, and (3) to provide a concrete example of how that approach can be used to predict diet mix. Specifically, an attempt is made to derive the shape of nutrient preference indifference curves with data from modern foragers, and then use these data to predict the diet of another modern foraging population. The most important contribution I hope to make, however, is to encourage other researchers interested in modeling foraging behavior to seek new solutions to the problem of predicting resource choice and diet under conditions when the food value from different resource types cannot be reduced to energy.

\section{FIELD TESTS OF OPTIMAL DIET MODEL PREDICTIONS}

The Optimal Diet Model (MacArthur and Pianka, 1966; Emlen, 1966; Charnov, 1973; Charnov and Orians, 1973) was designed to predict diet choice under conditions that do not seriously depart from the simplifying assumptions mentioned above. The model predicts the foraging strategy which will result in a single "optimal diet," which maximizes the overall energy acquisiton rate during the foraging period. The combination of resources which should be included in the "optimal diet" can be most easily calculated by measuring the energetic return rate from each resource upon encounter and then ranking them from highest to lowest (see Hawkes et al., 1982; Hill and Hawkes, 1983, for examples of this procedure using data derived from human foragers). Starting with the top-ranked resource and then considering the others in descending order of their caloric return rate, one can calculate how many, and which resource types should be included in the diet in order to maximize mean energetic foraging return rate.

If we assume that the energetic costs of exploiting different resources do not differ seriously (when they do, calculations should be based on net acquisition rate), the optimal diet model rule can be stated mathematically as follows (from Charnov and Orians, 1973): $E=$ total calories acquired foraging, $T=$ total time spent foraging, $t_{s}=$ search time, $e_{i}=$ energy available in a unit of resource $i, h_{i}=$ handling time per unit of resource $i, r_{i}=$ units of resource $i$ encountered in a unit of search time $t_{s}$. By definition $T=t_{s}+$ $\Sigma h_{i} r_{i} t_{s}$. 
According to the optimal diet model the forager should maximize mean foraging return rate, or

$$
E / T=\frac{\Sigma r_{i} \cdot e_{i} \cdot t_{s}}{t_{s}+\Sigma r_{i} \cdot e_{i} \cdot t_{s}}=\frac{\Sigma r_{i} e_{i}}{1+\Sigma r_{i} \cdot e_{i} \cdot t_{s}}
$$

Thus, an item $j$ should only be included in the diet when encountered if

$$
E / T \leq e_{j} / h_{j},
$$

since adding the energetic value and handling time to the numerator and denominator respectively will increase the mean foraging return rate. In addition, for some item $a$ not in the optimal diet, the following inequality must hold:

$$
\frac{\Sigma r_{i} e_{i}}{1+\Sigma r_{i} h_{i}}>\frac{\Sigma r_{i} e_{i}+r_{a} e_{a}}{1+\Sigma r_{i} h_{i}+r_{a} h_{a}}
$$

which implies that $E / T>\frac{r_{a} e_{a}}{r_{a} h_{a}}$ or $E / T>\frac{e_{a}}{h_{a}}$

In English, the optimal diet rule (called the prey algorithm in Stephens and Krebs, 1986) states that if resources are considered one at a time according to descending profitability $(e / h)$, all resources characterized by return rates higher than the forager can acquire from exploiting only higher ranked resources should be included in the diet, because they will increase the mean foraging efficiency. The first resource in the descending profitability ranking which will decrease mean foraging efficiency when included in the diet should not be exploited when encountered, and all other lower ranking resources should also be ignored by the forager. Such a foraging strategy will maximize $E / T$ (net rate of energy gain) when the assumptions of the model are met. The rule leads to three interesting predictions: (1) that resource types are either always taken upon encounter or never taken upon encounter, (2) that types will be added or dropped from a foragers diet according to their energy profitability rank $(e / h)$, and (3) that the inclusion or exclusion of a resource type in the optimal diet is independent of its encounter rate.

The diet model as developed is actually a model describing diet choice principles rather than predicting the actual diet. It is designed to predict foraging decisions when resources are encountered, but does not consider the search path that a forager might use to increase or decrease encounter rates with specific resources (patch choice models do this). When foragers search randomly, however, the model does predict diet breadth (the array of resources that should be exploited), and diet breadth in combination with densities or actual encounter rates can be used to predict the average expected diet. 
Nevertheless, this has not been the goal of most applications of the model, which have instead focused on whether the three predictions above are met.

Despite the multiple restrictive assumptions of the optimal diet model, some of its predictions were tested on a group of modern human foragers, the Ache of Paraguay. The Ache forage in an environment which appears to satisfy the assumptions underlying the optimal diet model. This is because most food resources acquired by the Ache appear uniformly or randomly distributed on cursory inspection. Undoubtedly, some resources are patchily distributed (random transects have confirmed this), but game items and honey which constitute the major part of the Ache diet (Hawkes et al., 1982; Hill, Hawkes, Hurtado, and Kaplan, 1984) do not seem to be distributed in patches whose locations are well known or predictable to the Ache. Instead, Ache foragers move through the environment, searching in an opportunistic fashion for any of a large number of resources (see Hawkes et al., 1982; Hill and Hawkes, 1983; Kaplan, 1983; Hurtado, 1985, for descriptions). When resources are encountered, the choice facing the Ache forager is whether to attempt to exploit the resource or to ignore it and move on in search for other resource types (or patches).

Several recent papers (Hawkes et al., 1982; Hill and Hawkes, 1983; Hill et al., 1987) describe tests of some predictions from the optimal diet model using Ache foraging data. Although it is not possible to measure the return rates of all of the numerous potential resource types in the forest which the Ache do not exploit, the prediction which can be tested is that each resource type observed exploited must increase the overall foraging return rate when it is taken, compared to what could be obtained if it were ignored. If the optimal diet rule is completely adhered to, the mean return rate upon encounter for each resource observed exploited must be greater than or equal to the measured mean foraging return rate. The probability of this prediction being met if resource types are randomly chosen without respect to their profitability is quite low (Hill et al., 1987).

Results show that almost all resource types observed exploited by Ache foragers do increase overall foraging return rates relative to that which would be obtained if they were ignored (Hawkes et al., 1982; Hill and Hawkes, 1983), and most items taken by both male and females foragers give higher returns upon encounter than are obtained from foraging in general (Hill et $a l ., 1987)$. However, many resource types are not completely included or excluded upon encounter, as predicted from the optimal diet model (Fig. 1 and 2 ). Instead some resources are taken only occasionally when encountered. In addition, resources are not necessarily included or excluded from the optimal diet according to the mathematical predictions (Eqs.) (1) and (2). This also means they are unlikely to be included or excluded according to their rank order when foraging conditions change. 


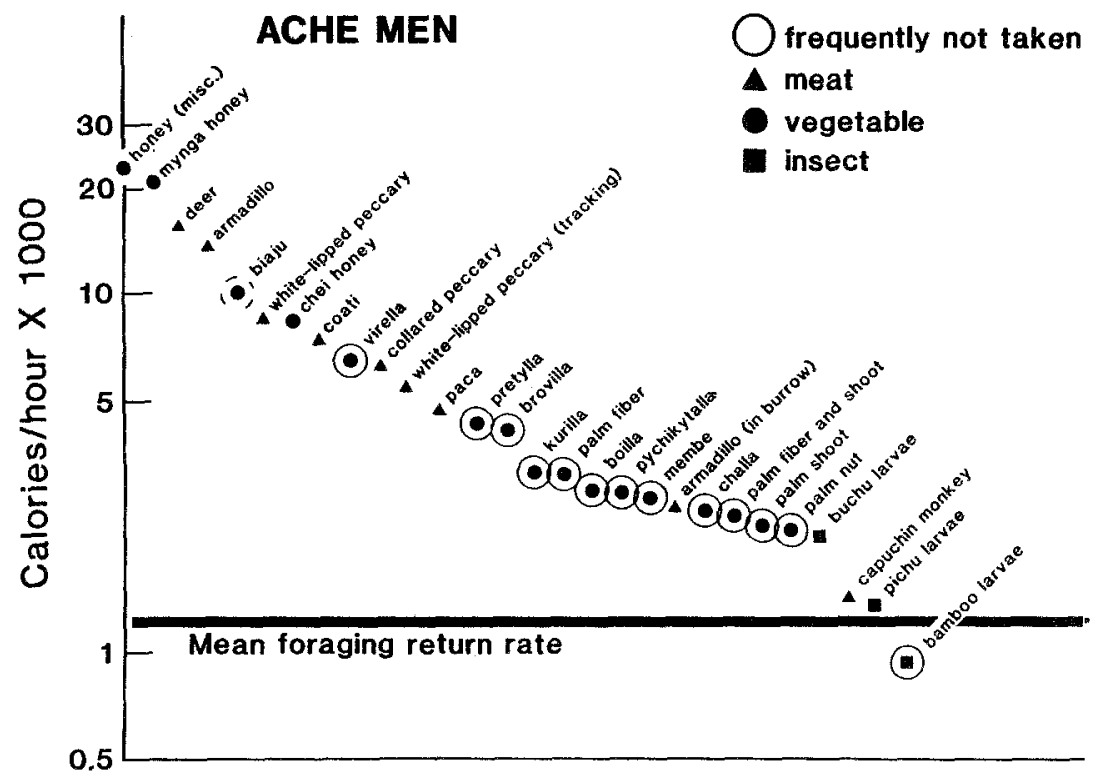

Ranked resources

Fig. 1. Men's foraging return rates from individually-ranked resources. Beginning from the highest return resources on the left side, the return rate of each resource upon encounter is shown and compared to the mean overall foraging return rate for men. The optimal diet model predicts that all resources included in the diet should be characterized by return rates higher than mean overall foraging returns. Resources frequently ignored when encountered ar circled. Mean probability of rejection upon encounter with circled items is $0.55(45 \%$ of encounters are pursued, $n=29)$. Probability of rejection upon encounter with biaju is $0.27(n=15)$. For other resources probability of rejection $\cong 0$.

Recently collected and analyzed Ache data show some foraging patterns incongruous with the model. For example, Ache men frequently pass by high ranked resources without trying to exploit them (Fig. 1). These resources clearly increase mean foraging return rate when they are exploited. Because field observers are unable to perceive resource encounters at the same rate as the Ache can, we cannot precisely quantify how often the resources in question were encountered and ignored. However, many times the resources circled in Figs. 1 and 2 were pointed out to observers and subsequently not pursued. This almost never happened for the resource types not circled. Interestingly, all the resources which men pass by, but which would increase their overall foraging return rate if exploited, were vegetable items. The lack of male interest in vegetable encounters is evident in total food production data. Men acquired $87 \%$ of all food consumed, but men collected less than $20 \%$ of the total vegetable food (Hurtado, Hawkes, and Kaplan, 1985) and spent only $2 \%$ of their foraging time pursuing vegetable resources (Hill and Hawkes, 1983). 


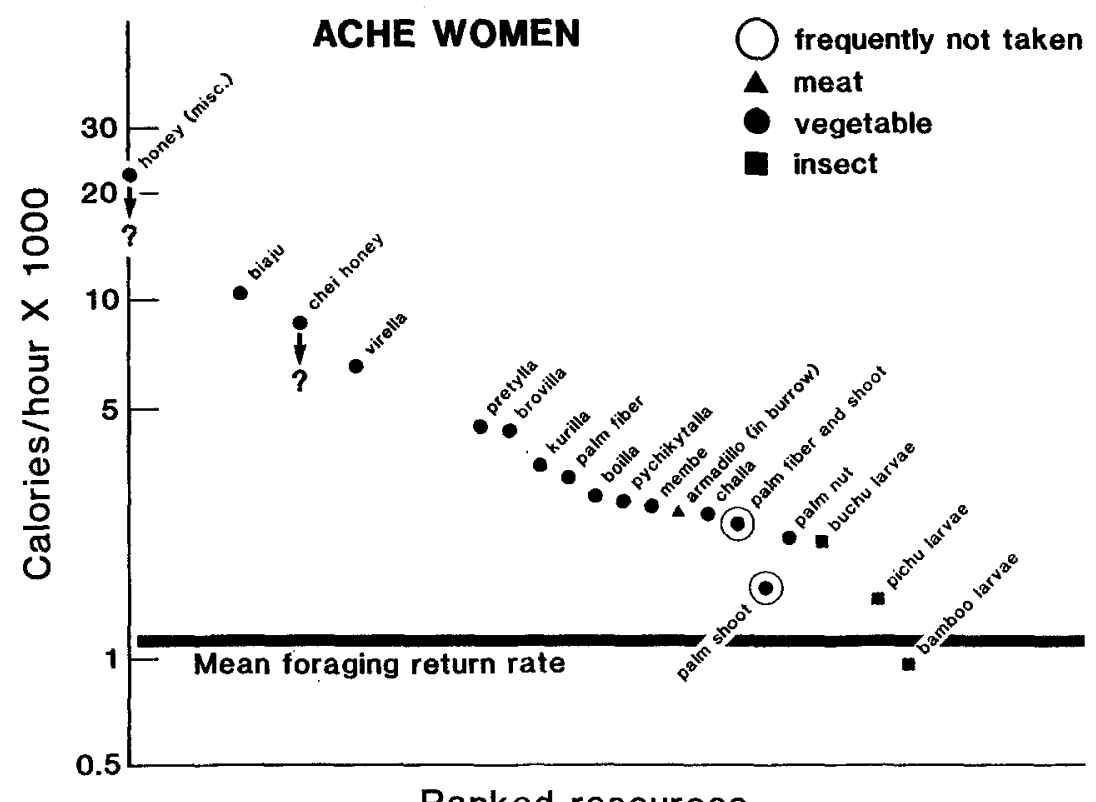

Fig. 2. Women's foraging return rates from individually-ranked resources (as in Fig. 1).

Ache women on the other hand show a different pattern (Fig. 2). They fail to exploit several high-ranked meat resources that they encounter even when those resources types are much more profitable than women's mean foraging return rate. We do not actually know what the current return rate for women's hunting is, or what that return rate would be if females spent the same amount of time learning and training to hunt that males do. This statement about profitability is therefore based on the observed male return rate. Virtually all of the high-ranked resources excluded by women are mammalian game animals. Finally, both sexes pursue one resource, bamboo larvae, which gives a lower energetic return rate upon encounter than can be gotten from foraging in general (in this sample at least), and thus lowers their overall mean foraging return rate.

In this paper, I will not consider why women do not pursue high-ranked game items that could increase their mean foraging return rate. Hurtado et al. (1985) and Hurtado (1985) have suggested that Ache women might seriously increase their offspring mortality rates, or decrease their own fertility, if they were involved in certain categories of activities, including hunting of mammalian game animals. If this is true, it means that some possible female foraging strategies may be eliminated for reasons other than food considerations. 
Although 26 of 27 resources taken by Ache men are characterized by return rates higher than the mean foraging return rate (as predicted by the optimal diet model) the foraging pattern of Ache males does not meet several of the model's predictions. Because high-ranked vegetable resources are not pursued, the optimal diet predicted from the optimal diet model may not actually include many of the lower-ranked items observed taken by Ache men. If all high-ranked items, including vegetable resources, were always taken upon encounter as predicted, the mean caloric foraging return rate for Ache men would probably be considerably higher. Thus, many of the lowerranked resource types which have profitabilities above the currently observed foraging return rate might in fact lower the potential overall foraging return rates. This possibility is indicated by recent data on the densities of highranked vegetable items.

Hill et al. (1987) made two observations that suggest that Ache males could significantly increase their mean foraging return rate if they exploited more vegetable resources upon encounter. First, Ache women, on days when they do not spend time moving camp possessions and children, achieve a higher mean energetic foraging return rate than men do on those days, or all other foraging days. This means that men are choosing a lower caloric return foraging strategy than women choose. Second, aerial photos and ground transects suggest that palm densities in Paraguay are high enough that if men foraged for palm fiber alone, all day long, they could achieve a foraging return rate of 2630 calories per hour. This suggests that all resources characterized by return rates lower than 2630 calories per hour should be excluded from the optimal diet. Instead, men opt to hunt almost 7 hours per day at a return rate of only 1340 calories per hour. This number includes some calories due to honey acquision, but is primarily meat (see Hill et al., 1984). Both of these observations suggest that something about hunting or its product, meat, is more attractive than vegetable collecting to Ache men. In fact, they suggest that acquiring half as many calories of meat per hour is more attractive to Ache men than an alternative foraging strategy that would produce twice as many calories in the form of starch.

Observations such as this may not surprise some critics of OFT who have always maintained that humans do not attempt to maximize the energetic return rate they can acquire from subsistence activities. Nonetheless, it is important to demonstrate with solid empirical evidence how simple OFT models fails, before we can decide how to modify them, or build new models, In addition, it is important to demonstrate the generality of the problem with data from several other foraging groups. Because of this, my colleagues and I have begun to collect foraging data on other South American foragers designed to further test the utility of the optimal diet model and determine the modifications which would increase its explanatory value. 
Table I. Yaminahau-Ranked Resources $(1986)^{a}$

\begin{tabular}{clrccccc}
\hline $\begin{array}{c}\text { Resource } \\
\text { rank }\end{array}$ & $\begin{array}{c}\text { Resource } \\
\text { type }\end{array}$ & $\begin{array}{c}\text { Total } \\
\mathrm{kg}\end{array}$ & Edible & Cal/kg & $\begin{array}{c}\text { Hours } \\
\text { pursuit }\end{array}$ & $\begin{array}{c}\text { Overall } \\
\text { resource } \\
\text { return rate }\end{array}$ & $\begin{array}{c}\text { Foraging } \\
\text { return rate }\end{array}$ \\
\hline 1 & Plantain & 589 & .65 & 1040 & 15.1 & 26,368 & 3135 \\
2 & Caiman & 33 & .65 & 2340 & 02.5 & 19,845 & 3458 \\
3 & Wakawa $^{b}$ & 7 & .65 & 1140 & 01.7 & 3,051 & 3452 \\
4 & Sungaro $^{b}$ & 52 & .65 & 1140 & 32.2 & 1,206 & 3010 \\
5 & Boca chico $^{b}$ & 28 & .65 & 0960 & 32.4 & 539 & 2601 \\
\hline
\end{tabular}

${ }^{a}$ Total search time- $111.9 \mathrm{hr}$, travel only to plantain patches $=63 \mathrm{hr}$, plantain only returns 398,157 $\mathrm{cal} / 51.1+63 \mathrm{hr}=5098 \mathrm{cal} / \mathrm{hr}$, and returns from all meat foraging $=.86 \mathrm{~kg} / \mathrm{hr} \times 1500$ $\mathrm{cal} / \mathrm{kg}=1290 \mathrm{cal} / \mathrm{hr}$.

${ }^{b}$ Local fish names.

In 1985, A. Magdalene Hurtado and I observed Cuiva (Hiwi) foragers of the Venezuelan savanna for 2 months. The Cuiva study population made first contact in the 1950's, and continue to hunt and gather using bows and arrows and metal-tipped digging sticks. Hurtado and Hill $(1986,1987)$ provide a general description of the population, foraging patterns, and diet. All search, pursuit, and processing times were recorded with stopwatches, and foods acquired were weighed with hanging spring scales (details of OFT methods are published in Hawkes et al., 1982; Hill and Hawkes, 1983). Caloric values of foods were assigned using or values for equivalent Ache foods (Hill et al., 1984).

Results from the Cuiva again suggest that there is a problem with using the optimal diet model to predict men's foraging behavior. Although the mean foraging return rates for men were higher than those for women, men often failed to pursue what appeared to be high profitability vegetable resources when encountered. The mean energetic foraging return rate for Cuiva men during the sample period was $3070 \mathrm{cal} / \mathrm{hr}$ (Hurtado and Hill, 1987). All seven of the game items that we saw Cuiva men acquire during this time period were characterized by higher return rates than the overall foraging mean as predicted by the optimal diet model, but so was the major vegetable staple at the time, jatsiro roots, which were not taken by men. Jatsiro roots provided a mean of approximately $8489 \mathrm{cal} / \mathrm{hr}$ upon encounter yet despite several encounters (probably many more than the field observers were aware of), Cuiva men never stopped foraging to acquire these roots. Digging tools were either available or could have been if men had intended to dig the roots while hunting. Instead men spent virtually $100 \%$ of their foraging time searching for and pursuing game items.

Data recently collected on the Yora of Peru also show problems with using the optimal diet model to predict men's foraging strategies. The Yora 


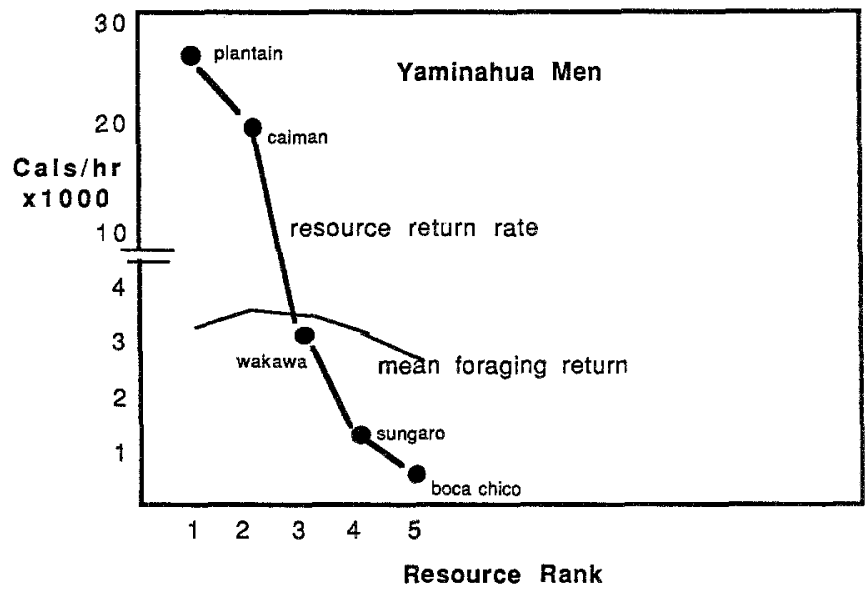

Fig. 3. Yora (Yaminahua) men's foraging returns for individually-ranked resources (descending line), and the mean overall foraging return rate that could be acquired as each resource is added into the diet (ascend. ing line).

live at the headwaters of the Manu river and made first peaceful contact in 1985. Hill and Kaplan (1988) provide a description of the study population, diet, and foraging strategies during the dry season of 1986. Again, it was possible to measure mean forating return rates, and return rates upon encounter for several different resource types (Table I). Yora men exploited five different resource types in the observed dry season foraging pattern. Calculations strongly suggest that the three lower-ranked resources should not be included in the Yora optimal diet (Fig. 3). Pursuing each of one of these resources upon encounter lowers the mean energetic foraging return rate of Yora men. Importantly, the low-ranked items which are included in the diet are all meat resources, and the highest-ranked resource which was frequently ignored is vegetable. The observation is also useful because it shows that even the simplest optimal diet model prediction, which states that all resources observed taken should be characterized by higher return rates than foraging in general, can easily fail to be upheld with empirical evidence.

Faced with these difficulties, it is useful to remember that simple optimal diet model predictions assume that energy returns will be maximized when all else is equal between alternative foraging strategies. We might consider hunting and vegetable collecting by men and ask whether there are significant differences between the two foraging strategies that could explain why men seem to favor hunting, or whether it is simply the energy-maximizing assumption itself that is likely to be incorrect. 


\section{HUNTING VS. GATHERING}

Most comparisons of hunting and gathering activities lead to the conclusion that hunting should be avoided when gathering can provide equal amounts of food. For example, hunting seems to be associated with greater risk of injury. In approximately 225 days of foraging withy the Ache three serious wounds from animal bites were witnessed, six poisonous snake bites, and several arrow wounds, all of which were incurred while hunting. Hunting seems to be associated with greater exposure to heat, cold, and moisture in the Ache case, as well as greatly increasing the risk of becoming lost (something we observed several times). Because hunting takes place at a greater distance from the social group it may make individuals more vulnerable to hostile attacks from enemies, and means that any serious injury may result in death because of lack of assistance. The results of this greater danger can be demonstrated in the most extreme form by comparing Ache male and female death rates from accidental causes (snake bite, jaguar, falling out of a tree, getting lost, etc). A sample of 169 adult Ache deaths shows $16 \%$ of male deaths and only $4 \%$ of female deaths from accidental causes.

A second difference between hunting and gathering is that, in general, hunting is probably more energy expensive than gathering (Montgomery and Johnson, 1977), and therefore leads to lower net energetic gains when gross energetic return rates from meat resources and vegetables resources are equal (all numbers used in this paper are gross energetic return rates). This again would lead to hunting being a less favorable alternative than gathering. Other differences between hunting and gathering may, however, lead to hunting being the preferred strategy even when the mean number of calories acquired per unit time is lower.

One possible reason to favor hunting over gathering is that the daily variance in food production associated with hunting is probably considerably higher under most circumstances. While many models of foraging behavior consider variance reduction a likely goal of foragers, Hawkes (1987) has developed a model which suggests that, under some conditions, a variancemaximizing strategy of food acquisition may be evolutionarily stable for males.

The most obvious difference between hunting and gathering, however, is that their products vary considerably in nutritional content. Specifically, hunting generally produces resources high in protein and lipid content relative to gathered resources. For example, the resources acquired by Ache foragers divide nicely into two categories (Table II). One category of foods, (fruits, roots, honey, palm starch, and shoots) is generally characterized by medium to high levels of carbohydrate but less than $2 \%$ protein and less than $0.5 \%$ lipid by weight. The other category of foods (meat, larvae, and nuts) 
Table II. Macronutrient Composition of Ache Foods ${ }^{\alpha}$

\begin{tabular}{lcccr}
\hline Resource & Protein (\%) & Lipid (\%) & Carbohydrate (\%) & $\mathrm{N}^{b}$ \\
\hline Meat & 23.6 & 5.6 & $<.01$ & 9 \\
Larva & 8.8 & 25.5 & $<.01$ & 4 \\
Nuts & 11.8 & 26.0 & 40.6 & 1 \\
Fruits & 2.0 & 0.5 & 5.0 & 22 \\
Palms & 2.0 & 0.5 & 9.4 & 16 \\
Roots & 1.6 & 0.3 & 16.8 & 7 \\
Honey & 0.2 & $<.01$ & 78.0 & 1 \\
\hline
\end{tabular}

${ }^{a}$ Percent by weight.

${ }^{b}$ Sample size.

${ }^{c}$ From published tables (Leung, 1961).

is characterized by protein levels in the range of $8-30 \%$, and lipid content from $5-30 \%$ by weight with generally low carbohydrate levels.

Referring back to Figs. 1 and 2, it is striking that all high-ranked resources that are ignored frequently by Ache men are carbohydrate rich but protein-lipid poor. Most of the lowest-ranked resources that are generally taken by Ache men or women are protein-lipid rich. The one resource (bamboo larvae) taken by Ache men and women that clearly lowered their mean foraging return rate is characterized by moderate protein levels $(9 \%)$ and very high lipid levels $(32 \%)$.

Faced with evidence that differences in resource macronutrient content may be great enough and of enough biological significance to seriously undermine the predictions from models based on the assumption that energy returns will be maximized by foragers, how can we proceed? Is there a simple way to incorporate multiple nutrient goals into optimizing models of foraging behavior, and what assumptions are built into alternative approaches to this problem?

\section{NUTRIENT COMPLEMENTARITY AND INDIFFERENCE CURVE MODELS}

Theory on choice between multiple useful commodities has been mainly developed in economics and experimentally tested in psychology (see Stephens and Krebs, 1986, chap. 5, for short review). This approach, based on the use of indifference curves, has been occasionally borrowed by biologists and anthropologists to study tradeoffs between desirable alternative resources (Covich, 1972; Rapport, 1971, 1980; Tilman, 1982) or time allocation to activities (Hawkes et al., 1985; Winterhalder, 1983). In economic models, choices are assumed to maximize utility, which is a descriptive term approximately equivalent to the satisfaction derived from a com- 


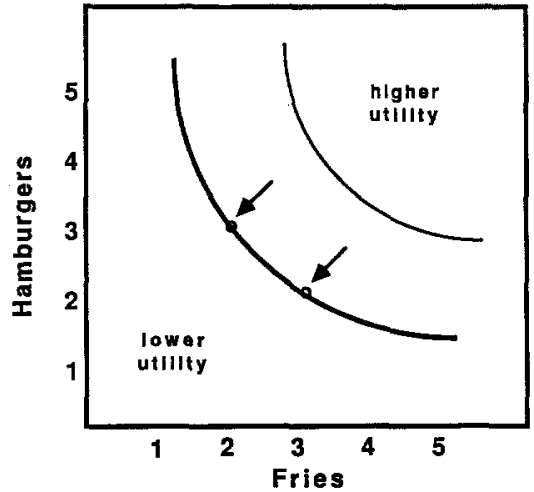

Fig. 4. Simple indifference curves. All combinations that lie on the same line provide equal utility to the consumer arrows. Combinations on indifference curves further from the origin provide higher total utility.

modity. Biologists generally substitute inclusive fitness or some proximate goal assumed to correlate with fitness in place of utility, in order to achieve theoretical closure.

The indifference curve approach begins with the assumption that for any two desirable resources, a number of different combinations of the two resources would define a line of equal satisfaction or fitness (Fig. 4). Thus, for example, perhaps a combination of 3 hamburgers and 2 fries would provide the same utility as the combination of 2 hamburgers and 3 fries. The line defined by these points is called an indifference curve, because the consumer should be indifferent to the various combinations on the same line. Many such curves should exist for any two resources (see Fig. 4), and any package or combination on an indifference curve further from the origin (e.g., four hamburgers and three fries) should always be preferred, as it provides higher total utility. Thus, indifference curves are isoclines (analogous to thermoclines or contour lines) where each isocline represents the set of all combinations of equivalent value, and the isoclines further from the origin represent higher value combinations than those near to the origin.

The utility relationship between the amount acquired of two resources and subsequent fitness can often be characterized by two extremes (Tilman 1982, for discussion). Some resources may be perfectly substitutable, and others may be perfectly complementary (thus essential). Most probably lie somewhere in between these extremes (partially substitutable and partially complementary). For perfectly substitutable resources, e.g., $10 \%$ sucrose solution vs. $20 \%$ sucrose solution, the utility value from an increment of resource A can always be matched by a constant increment of resource $B$. The indifference curve describing this relationship is a straight line (Fig. 5a) which intersects both the $\mathrm{x}$ and $\mathrm{y}$ axis. The assumption of perfect substitutability is built into all OFT models that measure food value in calories only.

Perfectly complementary resources are those for which the utility value derived from a given amount of each resource is totally dependent on the 


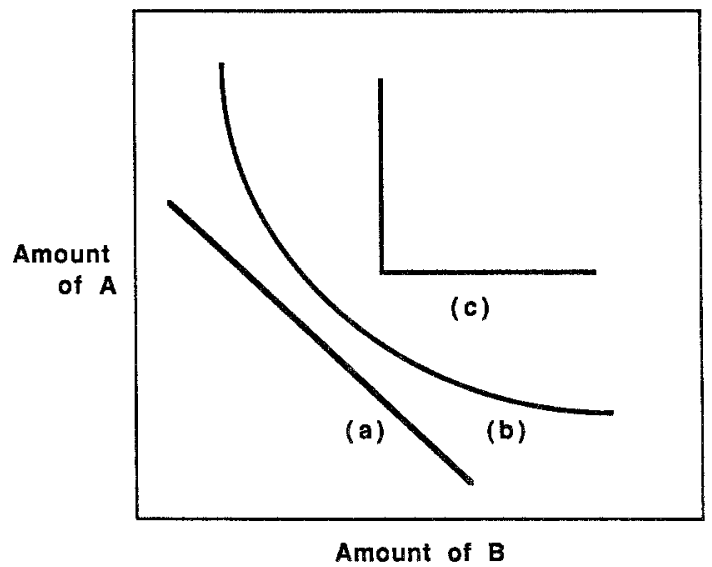

Fig. 5. Some of the possible shapes indifference curves may take: (a) perfect substitutability, (b) partial complementarity, and (c) perfect complementarity.

amount of the other resource that is available, e.g., nuts and bolts. The indifference curve describing the value derived from perfectly complementary resources is a line that forms a $90^{\circ}$ angle. This line never intersects the $\mathrm{x}$ or y axis, indicating that some amount of each resource is absolutely essential to achieve any fitness level. Acquisition of additional amounts of one resource beyond that required to complement the other resource will not lead to an increase in utility (Fig. 5c).

But, for many pairs of useful commodities, the relationship between amounts acquired of each and associated fitness, is likely to be intermediate between the two described extremes. Partial substitutability and partial complementarity (Fig. 5b) should characterize the resources. This is especially likely for food types, because they are composed of combinations of different macro- and micronutrients in differing amounts.

Since it is often the case that increasing intake of a single nutrient will provide corresponding by fewer benefits per increment as the amount consumed becomes greater and greater, the relationship between nutritional benefit and amount consumed for many nutrients might be described by a negative accelerated line (or diminishing returns; Fig. 6). When this is true for several alternative nutrients, it means that the forager should prefer to acquire as much as possible of each different nutrient, but the degree to which he prefers each depends on how much of each he already has. If the value of each resource is also dependent on the amounts available of the other resources (defined as complementarity above), a forager, given limited time available, should forage in such a way as to acquire the combination of nutrients which will lead to the highest utility or fitness benefits. 


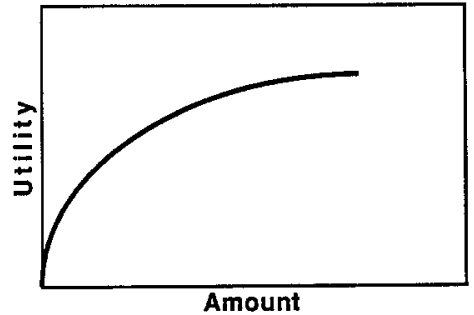

Fig. 6. Diminishing returns curve. As the amount of a resource consumed increases, the utility value of an additional increment decreases.

When resource pairs consist of many nutrients in common, but one or more essential nutrients that are unique to each, the resource pairs are likely to be characterized by an indifference curve something similar to line $b$ in Fig. 5. But, since all of the three macronutrients, carbohydrate, protein, and lipid can be converted into energy, whereas some essential amino acids and fatty acids cannot be produced by the body, it is likely that the indifference curves for protein or lipid and carbohydrate intersect the protein or lipid axis but not the carbohydrate axis (Tilman, 1982, calls this type of indifference curve "hemi-essential"). This means that diets of pure protein or lipid may lead to some level of utility, whereas diets of pure carbohydrate will inevitably lead to death. As will be clear, the precise shape of an indifference curve for two resource alternatives is crucial to the model as it can be used to predict how much of each will be preferred under known conditions of available income and resource costs.

Using the indifference curves approach to consumer choice, three factors must be specified in order to predict the optimal mix of resources that should be acquired: (1) the income available, (2) price of commodities, and (3) the shape of the indifference curve set. Income is defined as the available time, energy, money, resources, etc., to be expended on the two commodities. In foraging decisions, the income to be expended is the time available for foraging. Although the amount of income that should be expended can be modeled using indifference curves (Hawkes et al., 1985; Winterhalder 1983) for many foraging problems (including the protein-lipid/carbohydrate tradeoff problem in this paper), it is useful to take income as a given and consider how price changes in different commodities might affect the mix of resources acquired. The price of a commodity is the income that must be expended to acquire a given amount. Since the income in foraging problems is time available for foraging, the price of commodities is equivalent to time spent per amount of food acquired. This is the inverse of the return rate for a resource, patch, or foraging strategy.

A quick example of how income, price, and the shape of the indifference curves can be used to predict the optimal (highest utility) mix of two commodities will be instructive (this example follows closely that used by 

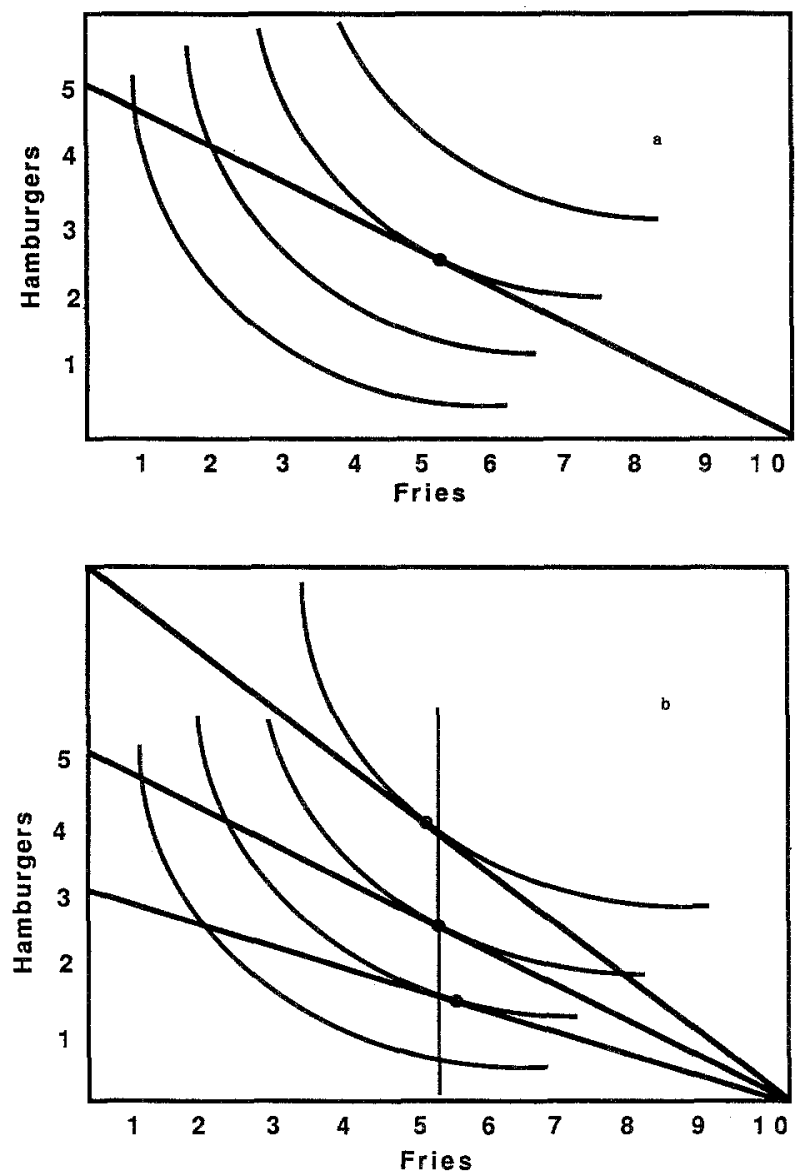

Fig. 7. Determination of the combination that provides highest utility. The point where the budget line is tangent to the highest indifference curve defines the combination of highest utility on a fixed income (a). As the price of one resource increases or decreases, the combination that provides highest utility changes (b).

Stephens and Krebs, 1986, chap. 5). Suppose that a consumer has only $\$ 5$ to spent (income) and that hamburgers cost $\$ 1$ each whereas fries cost only $\$ 0.50$ (prices). The consumer would be constrained to acquire a package consisting of not more than five hamburgers, or ten fries, or any combination of the two that lies on line $\mathrm{AB}$ (budget constraint line) joining the two together (Fig. 7a). The budget constraint line describes all possible combinations of resources that can be acquired with a specified income level. If we choose a set of indifference curves which imply that hamburgers and fries are only partially substitutable, the model allows us to specify the consumer 
choice that will maximize utility. It is the resource mix defined by the point where the budget constraint line is tangent to the highest indifference curve (Fig. 7a). In our example, the optimal mix consists of about 2.8 hamburgers and five fries (a modification of the model will be necessary if resources come only in whole units).

Now let us consider the effect of price changes. If the price of hamburgers increases, the slope of the budget constraints line becomes more shallow, and the predicted mix of hamburgers and fries shifts in favor of more fries (Fig. 7b). Similarly, if the price of hamburgers decreases, the slope of the budget constraint line becomes steeper, and the predicted resource mix shifts in favor of more hamburgers (Fig. 7b). It will be noted that price changes are expected to lead to large shifts in the observed mix of commodities chosen if the commodities are highly substitutable, whereas only small changes in the observed mix are expected with highly complementary commodities. This is because when the indifference curve bends sharply, most budget lines regardless of slope will be tangent to the curve in the region of the bend. Several experiments with rats have generally upheld this prediction (see Rachlin, Battalio, Kagel, and Green, 1981).

To summarize this section, according to the indifference curves model, the mix of resources chosen by a consumer is assumed to maximize utility. The precise resource mix which maximizes utility is determined by available income, prices of the commodities, and the slope of the indifference curve that characterizes the relationship between amounts of the commodities and the utility derived from those combinations. Different price ratios for commodities determine a budget constraint line, and the point on that line which is tangent to the highest indifference curve defines the highest utility resource mix. Now let us return to the problem of the apparent non-equivalence of meat and vegetable resources for human foragers, and see whether the indifference curves approach provides any hope for a solution.

\section{A MEAT/VEGETABLE FORAGING MODEL}

In this section, I consider the problem presented by empirical evidence from human male foragers concerning meat and vegetable foraging choices by investigating two simple decision situations. First is the decision facing the forager about how much time to spend in each of two mutually exclusive activities which produce meat or vegetable/carbohydrate. The activities are mutually exclusive either because they take place in different areas in twodimensional space or they require different tools. This is essentially a patch choice model with two patch types. The second is how the forager decides whether or not to pursue a single resource upon encounter while foraging in a non-patchy environment with a known expected return rate for the other 


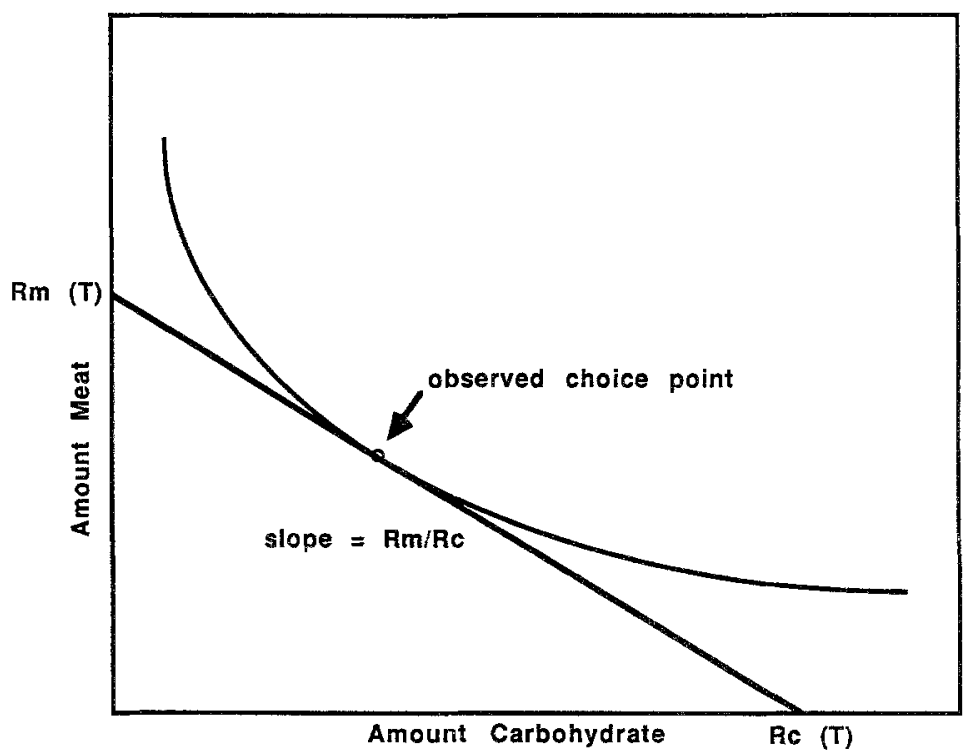

Fig. 8. An indifference curve model of the meat/carbohydrate foraging tradeoff.

resource type (either meat or vegetable). This decision is very similar to the type of decision considered in the simple optimal diet model.

A model of the protein-lipid/carbohydrate tradeoff decision using indifference curves is shown in Fig. 8. Ideally, each macronutrient should be considered separately, however, since meat is the primary product of male foraging activities, and it includes both high lipid and protein in the same package, these two macronutrients are combined to simplify the model. If we let: $T=$ total time spent foraging, $R_{m}=$ meat return rate, and $R_{c}=$ carbohydrate return rate, the budget constraint line will have a y intercept of $R_{m}(T)$ and $\mathrm{x}$ intercept of $R_{c}(T)$. The slope of the line is $R_{m} / R_{c}$ which is independent of the income value. The mix of resources which maximizes utility/fitness is the point where the budget constraint line is tangent to the indifference curve furthest from the origin.

This model describes the tradeoff faced by the forager, and the solution (diet choice point) which will maximize utility. According to the model, the optimal mix of meat and vegetable acquired by a forager depends on three things: (1) the fitness effect of different amounts of meat and vegetable input, this relationship is described by the shape of the indifference curve, (2) the relative return rates, i.e., amount acquired per unit time, or price, characterizing meat and vegetable resources; this determines the slope of the budget constraint, and (3) the amount of time available for foraging (income). If this model is correct, it suggests that knowing the return rates for resource 
types across a variety of conditions, and the diet that is chosen in each case, will allow one to solve for the shape of the indifference curve. Knowing the shape of the indifference curve and the return rate for various resource types will allow us to predict the diet of a foraging group.

There are several assumptions associated with this graphic model as it has been presented. First, meat and carbohydrate acquisition strategies are assumed to be mutually exclusive such that each can be thought of as a separate patch and no shared search or handling time for the two resource classes is possible. Second, the forager can spend any amount of time (up to total foraging time) in either patch, and the two patches are close enough that no time is lost switching from one to the other. The reader may wonder about this, since the two decisions considered with this model seem to violate some of the necessary assumptions. The patch choice decision, for example, would sometimes seem to violate the second and third assumptions above, i.e., no time lost in switching and all tools available, leading to a convex budget constraint line. While this may be true over a short time period, or even on a daily basis, it is not neccessarily the case for longer time periods. For example, over the period of a week, the decision about which patch to exploit may be made a least once every day for a central place forager. Each morning he may decide in which direction to head off, and which tools to carry, thus making a patch choice decision. Patches are exclusive and no time is lost switching between them. Thus, over a long timespan, the assumptions producing a straight line budget constrain will be generally met. In some cases, patch choice decisions, meeting the assumptions of the simple model above, may be made several times each day, e.g., a mobile forager who has access to all his tools several times a day, depletes patches quickly, and knows where additional patrches of each type are at any point in time.

The decision faced upon encounter with a single resource while foraging may also violate the assumption about having the necessary tools at hand, but in such a case it is easier to simply treat the situation as if no encounter took place (since the resource can't be exploited without the tools). A more serious problem for applying the simple model arises because such decisions are likely to violate the second assumption, that any amount of time can be spent foraging in either activity involved in the decision. For any single resource encounter, only a specific short time period is likely to be expended. Thus, the decision concerns only how to forage in the next short time interval, i.e., income is not total foraging time available, and the decision cannot predict the total diet mix. This is similar to the situation faced by the classic optimal diet model, which can only predict whether a resource should be taken upon encounter, but not how much of that resource will be in the optimal diet. This qualification limits the way observed foraging patterns can be used to make diet predictions, but does not exclude the use of moment by moment decisions for deriving the shape of the indifference curve. Third, 
the forager has the tools and foraging abilities to exploit either patch at any point in time. Fourth, that resources are not perfectly substitutable (this assumption is represented by the shape of the indifference curve, but will be tested below).

The first three assumptions above are required in order for the budget constraint to form a straight line (the utility of this simplification will be clear in the next section). Since the budget constraint is defined by any possible combination of the two resources that can be acquired with a fixed income (during a given foraging period), the line may be concave, convex, or straight. If one resource is encountered while searching for or pursuing another, the budget constraint line will bow upward in the middle, indicating that more total food could be gotten if both resources were acquired when encountered, than if only one or the other resource is taken in a given foraging period (this should generally be true when resources are randomly distributed, but the effect is even stronger if there is a positive correlation in the encounter rates for two resources). If resources are patchily distributed such that it costs more, e.g, greater travel time, to switch patches than to exploit only one, or if different tools, abilities, or physiology, e.g., digestive enzymes, are necessary to exploit the two different resources, the budget constraint curve may bow downward in the middle, indicating that more food could be acquired by specializing just one resource than by taking a mix.

In order to use this simple graphic model for predicting how much meat and vegetables men should acquire when foraging, we must know the values of the three parameters. As in most foraging decision models, the amount of time foraging (income) will be taken as a given, because the goal is to predict only which strategies will be employed while foraging. The return rates of the two resource types are two independent variables in the model, and are likely to vary with ecological conditions both spatially and temporally. In order to predict the diet mix, however, we also need to know the shape of the indifference curve for the two resources (the third independent variable).

The shape of the indifference curve may be constant across a variety of conditions or it may differ somewhat. It is probably not too variable across populations since it is primarily a function of human biochemistry and physiology. The fitness value of different combinations of meat and vegetable will not be dependent on their return rate (price), but rather on the effects the different amounts of protein carbohydrate and lipids have on growth, survivorship, and reproduction in any ecological context. Although it is likely that the fitness effects of different nutrient combinations differ somewhat as a function of age, sex, reproductive state, environmental conditions, etc., the model will be simplified to assume that a single average indifference curve represents the biological value of different food combinations for all populations of foragers. 
There are several ways to determine the shapes of the indifference curves for protein-lipid-rich and carbohydrate-rich resources. These can be divided into techniques for producing a protein-lipid/carbohydrate fitness indifference curve, and a protein-lipid/carbohydrate preference indifference curve. The preferences observed are assumed to be shaped by natural selection, thus preference curves should generally match fitness curves if the relevant characteristics of the environment have not changed significantly from those present when the food preference mechanism evolved (one may wonder whether food preferences observed in modern Western societies lead to highest fitness since most human populations through history have probably been strongly food limited, and thus never able to achieve food consumption levels observed in some modern societies). To the extent that preference curves do not match fitness curves, the preference curves (which may be rules of thumb) should be better predictors of foraging decisions.

Derivation of fitness and preference indifference curves from current knowledge about human biochemistry, physiology, and nutrition would be most satisfying. Unfortunately, we do not yet know enough about human nutrition to do this. This is primarily because most nutrition research has been aimed at determining minimal nutritional requirements, or the effects of very poor diets, rather than determining the biological effects of "adequate" diets of alternative composition. Alternatively, we could derive fitness indifference curves by measuring the effects of different dietary combinations on fitness, or proximate measures of fitness such as weight gain, adult size, reproductive hormone levels, interbirth interval, outcome of mating competition, etc. These measurements could be made in naturally varying populations (especially for humans), or experimentally, perhaps using nonhuman omnivorous mammals.

Some relevant experimental data along these lines already exist. For example, several studies show that rats fed isocaloric diets (diets of equivalent energy) grow best on the highest protein levels offered across a wide variety of protein levels (Donald, Pitts, and Dohl, 1980; Burkhardt, Mercer, Schweisthal, and Cole, 1982). These studies show increases in growth rates with protein making up to $25 \%$ of the total calories in the diet, a level rarely achieved in measured human diets (however, a rough calculation of the Ache diet as reported in Hill et al., 1984, shows $39 \%$ of the calories in the diet come from protein, $21 \%$ come from fat, and $40 \%$ from carbohydrate). This trend also appears to hold in experiments with human infants (Fomon, Thomas, Filer, Zeller, and Leonard, 1971) and adults (Miller and Munford, 1967). Finally, a recent study with rats (Yoshimura, Kighi, Matsumoto, and Inove, 1982) suggests that the growth rate attained on any given level of protein is dependent on the carbohydrate available. This result indeed suggests 
true complementarity of the two macronutrients. However, these studies need to be followed up in order to determine if increased growth rates, or adult body sizes eventually lead to higher fitness.

A common method that can be used to determine the shape of meat/vegetable preference indifference curves is to conduct food choice experiments. Using this approach, different combinations and different resource prices are offered to an experimental subject, and preferences are recorded. Through a variety of trials, equivalent combinations to the consumer can be determined (see Rachlin et al., 1981 for some examples). Data from rats again suggest that dietary self-selection leads to a high protein-lipid diet mix, e.g., $33 \%$ of calories as protein, and $30 \%$ as lipid in Castonguay, Hartman, Fitzpatrick, and Stern, 1982), but results vary somewhat according to factors such as temperature (Leshner, Collier, and Squibb, 1971), genetic strain (Castonguay et al., 1982), texture characteristics of foods, etc. (see Blundell, 1983). Interestingly, dietary selection experiments suggest that omnivores allowed to choose their own diet without restrictions can achieve growth rates superior to that achieved with laboratory diets (Evvard, 1915).

Most data on self-selected diets and food preferences using human subjects come from studies of diet composition as a function of income, or among athletes when food income is unlimited. The general trend found is that percent protein and lipid in the diet generally increase as a function of income around the world, while percent carbohydrate decreases (see Jerome, Pelto, and Kandel, 1980). At training tables, athletes eat even greater percentages of their diet in the form of lipids and protein and less in the form of carbohydrates than do upper income Americans (Hickson, Wolinsky, Pivarnik, Newman, Itak, and Stockton, 1987). Of course, in addition to unlimited food income, athletes are characterized by much higher activity levels than other control groups. Interestingly, athletes eat much more lipid but less protein than do Ache foragers who are also very active (the athletes consumed $22 \%$ of calories as protein, $39 \%$ as fat, and $39 \%$ as carbohydrate).

Finally, the method of determining the shape of preference indifference curve most relevant to field anthropologists is to observe food choices made under naturally varying conditions. In other words, one can observe choices actually made by foragers under known conditions, and measure what happens to the mix of resource types acquired when foraging return rates for meat or vegetable acquisition strategies change. Using this method, we can gain important information from looking at either general foraging patterns (patch choice and total diet), or moment by moment decisions about encountered resources. Some examples of both types of decisions are used below to derive a protein-lipid/carbohydrate indifference curve using foraging data from three native South American groups. 


\section{USING HUMAN FORAGING DATA TO CONSTRUCT AN INDIFFERENCE CURVE}

Foraging data that include measures of the return rates for two alternative resources, and the dietary mix (choice point) of those resources acquired by a forager can be used to reconstruct the indifference curve that characterizes the forager's preference for combinations of the two. This is dependent on the assumption that the average composition of food acquired by a forager will closely follow the average preferences of the population. This assumption may be violated under some conditions, and will be discussed in the final section. It would be most useful to observe price changes through time and then record a series of diet choices that all lie on the same indifference curve. In practice this is extremely difficult because price changes of commodities are not likely to be compensated by changes in total income that allow the new combinations chosen to produce the same level of satisfaction as the initial combinations. This means that most choices observed will not be on the same indifference curve.

Since we cannot simply draw a line through each choice point to produce the indifference curve, and since there is no way to know how far apart the indifference curves are that each choice point is located on, we are forced to treat the information from each choice point as an independent piece of information. However, some properties of indifference curves are useful for tying all the information together. First, no indifference curve can touch or cross another (that would, by definition, make them the same isocline). Second, curves are limited to angles greater than $90^{\circ}$ with the vertical and horizontal planes being limiters unless toxic effects are expressed at high intake levels (Tilman, 1982). Given these conditions, a small amount of data on price ratios (return rate ratios) of resources and observed diet mixes chosen can quickly produce a limited set of most probable shapes for the the indifference curve that characterizes two resources. This is illustrated below with data from three native South American groups who were living entirely from foraged foods during data collection periods.

The data presented here suggests that the Yora include three resources in their diet that should be excluded if the goal of foragers was to maximize their caloric return rate. Because we know the location of all plantain patches in the Yora foraging range, and measured all travel times to fishing, hunting, and gathering areas, we are able to calculate the return rate from the plantain patch (collecting only plantains) and the meat patch (only fishing or hunting). Although the Yora often foraged in such a way as to acquire plantains and meat together (this would lead to a convex budget constraint), the decision can be modeled in such a way as to produce a straight line budget constraint, if we compare only those cases where they chose one patch to the exclusion of the other. 
When they travel only to the plantain patch, Yora men acquire approximately 5098 calories per hour. When they travel to a stretch of river where only fishing or hunting is possible, they acquire a mean of 1290 calories per hour. Thus, the budget slope is $-1 / 4.0$, the ratio of the two possible amounts that can be acquired in a foraging interval. The decision facing Yora men is how much meat or plantains they should acquire given this ratio of returns. According to our data on the Yora diet, the choice point (observed diet) is 1814 calories daily per capita of plantains and 447 calories daily per capita of meat. When the budget constraint line and the choice point are plotted (Fig. 9), a range of possibilities for the shape of the meat/plantain indifference curve can be determined.

If the diet choice point does represent the point on the budget constraint line tangent to the highest indifference curve, then the meat/plantain indifference curve must be characterized by a slope to the left of the diet choice point which is between the budget slope and vertical, and to the right of the diet mix point the slope of the indifference curve must be between the budget slope and horizontal (these are termed restriction angles). The figure shows one possible indifference curve that meets these restrictions. In this case the possible range of slopes for the indifference curve to the right of the diet mix point is very small (because the restriction angle is very small), whereas the range of possible slopes of the indifference curve to the left of the diet

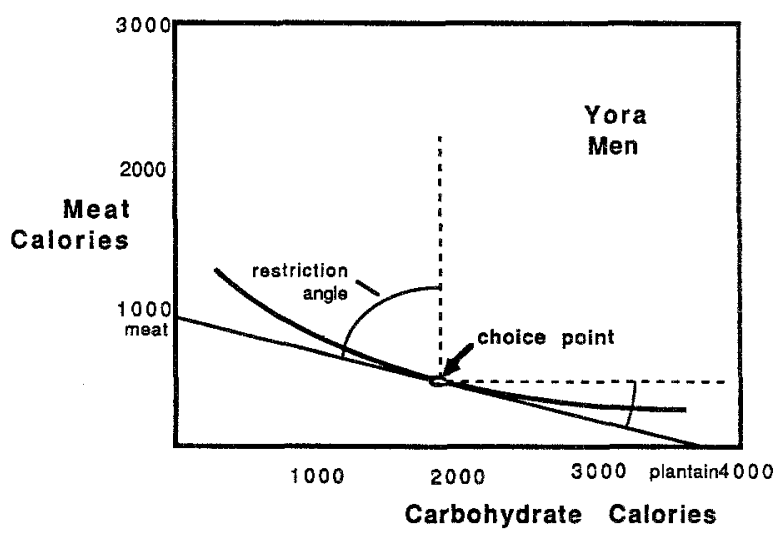

Fig. 9. Use of data from Yora men on return rates from plantain collecting, riverine hunting, and diet to acquire information on the shape of the meat/carbohydrate indifference curve. Because macronutrient indifference curves can have a maximum slope of vertical on the left and a minimum slope of horizontal on the right, the budget line and the choice point can be used to mark restriction angles for the indifference curve. The curve must lie somewhere inside the restriction if observed choices maximize utility of consumers. 
mix point is quite large (the restriction angle is large). This means that this specific empirical case has given us a good deal of information about the shape of the indifference curve in the high carbohydrate low protein-lipid portion of the curve, but much less information about the shape of the indifference curve in the low carbohydrate and high protein-lipid areas of the graph.

Continuing with the same procedure, we can consider a patch choice decision made by Ache foragers. It was mentioned earlier that with the palm densities observed in the forest where the Ache forage, men should be able to acquire approximately 2630 calories per hour exploiting only palms. Hunters acquire a mean of 1340 calories per hour primarily of meat. Some of the calories that are derived from the hunting strategy are actually honey, which is pure carbohydrate. This means the tradeoff is not strictly one set of macronutrients against the other, but since most of the calories acquired while hunting are meat, the approximation used here is roughly valid. Foraging decisions made during times of the year when no honey is produced are in agreement with the conclusion here, but result in a slightly smaller restriction angle, as the budget slope is shallower. Because palms are so dense, chosing the palm acquisition strategy would effectively eliminate any chance to hunt, so Ache men face a patch choice decision each day. The return rates from the two alternatives define the budget slope, but the diet choice point is somewhat problematic. Unlike the Yora, Ache men do not provide virtually all the food consumed by the group. Instead, Ache women provide about 975 calories per consumer per day of vegetable food and all food is shared with men and children. We can incorporate this contribution to the choice point into the Ache men's decision by taking the women's contribution as a given, and moving the $y$ axis over to the new starting point for Ache men (corresponding to the amount on the $\mathrm{x}$ axis that women will contribute).

From the new start point, the Ache men chose to spend virtually $100 \%$ of their foraging time in the hunting strategy. Thus, we can draw the budget slope $(-1 / 2.0)$ through the diet choice point and then consider the possible restrictions placed on the shape of the indifference curve (Fig. 10). This decision gives us no information about the slope of the indifference curve to the left of the choice point (because these diets were not possible to obtain), but limits the slope of the indifference curve to the right of the choice point such that it must be between the budget slope and horizontal. The information provided by the new restriction angle is in agreement with that obtained from the Yora decision, namely that the indifference curve has a very shallow slope at medium to high carbohydrate values. In this case, however, we also learn that the slope is shallow at many carbohydrate values even when the meat values are also high.

Now consider some moment by moment decisions that are made upon encounter with a resource. As described earlier, Cuiva men obtain approxi- 


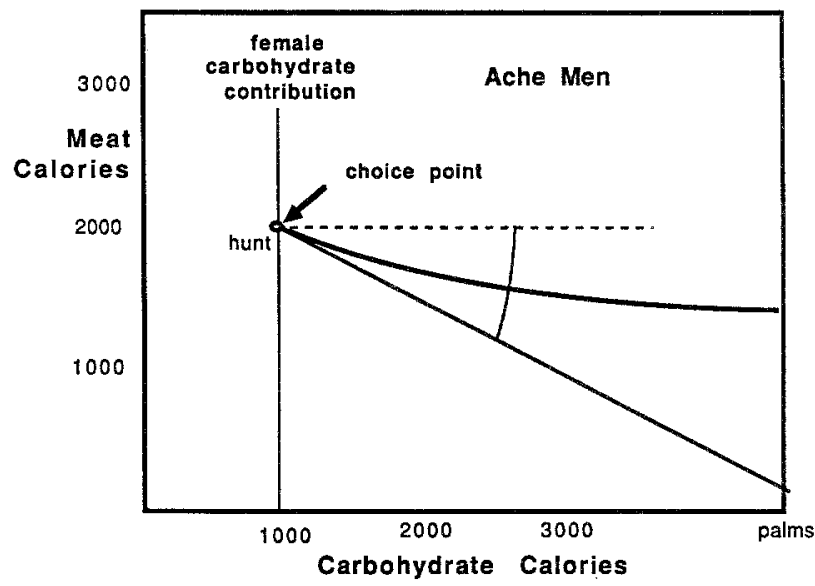

Fig. 10. Use of data from Ache men on hunting and palm fiber return rates to determine the restriction angle of the observed foraging behavior. The y axis must be moved to the right to allow men's decisions to take into account what they expect women to do.

mately 3070 calories per hour while hunting, and could acquire almost 8500 calories per hour upon encounter with jatsiro root patches. As in the Ache case, we must take the Cuiva women's contribution of about 800 calories daily per capita of carbohydrate as a given, and look at the men's choice point with that in mind. When Cuiva men encounter root patches they can stop hunting to exploit the roots, or continue hunting. The choice they make is always to continue hunting. These data again provide the budget slope and the choice point of the forager (Fig. 11) which restricts the slope of possible protein-lipid/carbohydrate indifference curves. As in the Ache case above, it provides no information about the slope of the indifference curve to the left of the choice point (those diets are not possible given the women's contribution) but it does limit the slope to the right of the choice point such that it must be between the budget slope and horizontal. Because the new choice point contains less carbohydrate than the previous two cases, this new information is useful. It suggests that if the various utility level indifference curves are not too different in shape, the indifference curve in the region between about 800 carbohydrate calories (Cuiva) and 1800 carbohydrate calories (Yora) must have a slope steeper than $-1 / 4.0$ (Yora left side of choice point) but shallower than $-1 / 2.8$ (Cuiva right side of choice point). The indifference curves constrained in this way may vary in slope somewhat in the area from 450 calories daily per capita meat (Yora) and 1350 calories daily per capita meat (Cuiva), but they cannot vary too much or they would be likely to touch or cross other indifferent curves located between the two meat intake values. 


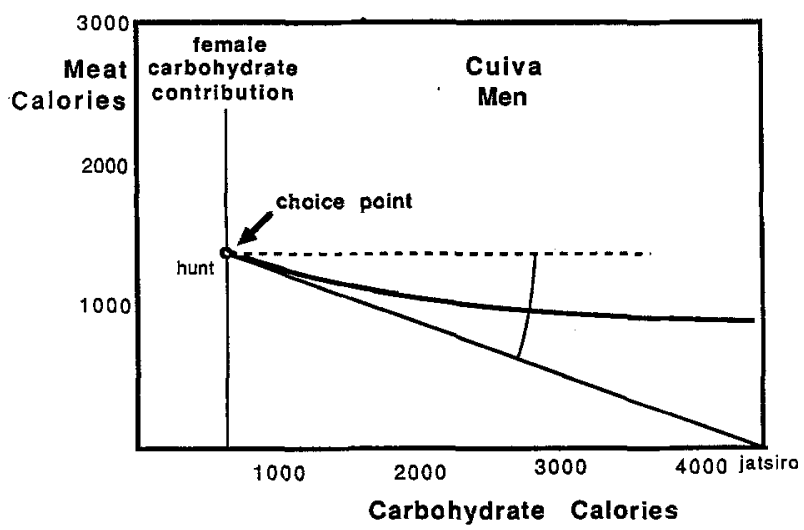

Fig. 11. Use of data from Cuiva men on hunting and jatsiro root returns to determine another restriction angle that limits the shape of the meat/carbohydrate indifference curve.

Another example of moment by moment decisions faced by Ache men will illustrate how observed choice points spaced apart can constrain the slope of the possible indifference curve within a region of the graph such that only a small range of slopes could meet the restriction criteria from the budget slopes associated with each choice point. As illustrated in Fig. 1, Ache men often pass by carbohydrate-rich resources while hunting. In fact, they almost never collect such resources, other than to eat a small amount if they are very hungry. One could plot the budget slope for each of these resources independently vs. hunting, but since each resource is passed by in favor of hunting, the highest return resource provides the most useful information. The information gained from plotting the budget slope and diet choice point for lower return carbohydrate resources is redundant, since if high return carbohydrate resources are passed by to continue hunting, there is little doubt that low return resources will also be passed by. The highest return fruit that men usually pass by upon encounter is virella (Fig. 1) which is abundant during the warm wet season (Hill et al., 1984) and is characterized by a return rate of about 6400 calories. On the other hand, during the same season, several types of honey, with a mean return rate of about 21,000 calories per hour were never passed by to our knowledge. Since the general foraging return rate for Ache men is 1340 calories per hour, and the pure meat return rate is about 910 calories per hour (Hill and Hawkes, 1983), this means the slope of the indifference curve between the choice point for virella and the choice point for honey (see Fig. 12) is probably between $-1 / 4.8$ (general foraging/virella) and $-1 / 23.0$ (meat/honey). When men encounter virella, they choose between exploiting that fruit or continuing on with their normal forag- 


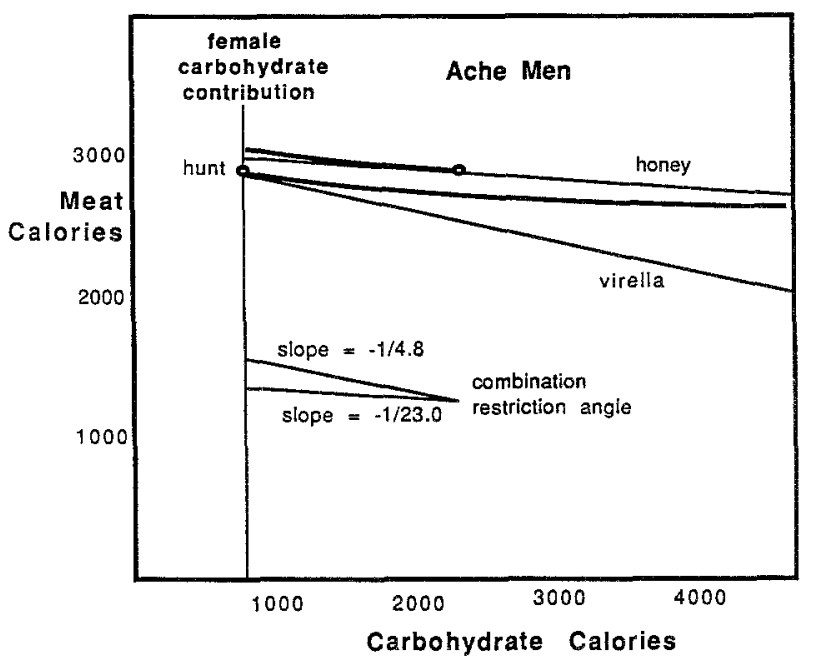

Fig. 12. Hunting vs. fruit collecting or honey extraction data which produces more restriction angles that limit the possible shape of the meat/carbohydrate indifference curve.

ing pattern which includes honey exploitation. This means the overall foraging return rate of 1340 calories per hour is relevant to calculating the budget slope. When men encounter honey, however, they can either ignore honey and acquire only meat (910 calories per hour), or they can take honey.

Each one of the five decisions described above for the Yora, the Ache, and the Cuiva, restricts the possible shape of the protein-lipid/carbohydrate indifference curve at a specific choice point on the graph. If we assume that a set of similar curves can be used to approximately describe the fitness value of different food combinations for all groups, there are very few possible indifference curve slopes that will fit the restrictions implied by each decision. Figure 13 shows the restriction angle implied by each decision and some of the few possible indifference curves that meet most of the restrictions without being likely to touch or cross. In the area for which we have acquired information (unshaded), the curve appears to be very shallow. The only two restriction angles that can't be met with the same curve simply moved up vertically are the Yora and Ache fruit choice points. These restriction angles suggest a slightly different indifference curve slope in the region of medium carbohydrate levels depending on whether the amount of meat available is low or high. This disagreement is quite small, however, and the implications will be discussed in the next section.

Approximate indifference curve slopes have been inferred from five decision situations in which South American foragers had to choose how much 
meat and carbohydrate to acquire, given specific return rates characterizing each resource type. The exercise suggests that with many more data points, it should be possible to construct an indifference curve that approximately characterizes the meat/carbohydrate tradeoff for human foragers. It should also be noted that every observed choice point, except for the case of the Ache meat vs. honey decision, violates the OFT prediction that energetic return rates will be maximized. Such an observation clearly points out the need for modifications to those OFT models which are based on the assumption that food types are perfectly substitutable and that food value can be measured in energy alone.

Thus, the indifference curves approach seems capable in theory of predicting decisions an organism will make between multiple desirable alternatives. The likely shape of such curves may be readily derived from the natural observed variance in foraging return rates, and decisions made by human foragers. At this point, however, we must look at the composite indifference curves generated in Fig. 13 with some skepticism. Is there any reason to believe that these indifference curves represent the fitness or preference values of meat and carbohydrate resources to human foragers? Can this curve be used to predict the mix of meat and carbohydrate in the diet of some other foraging group?

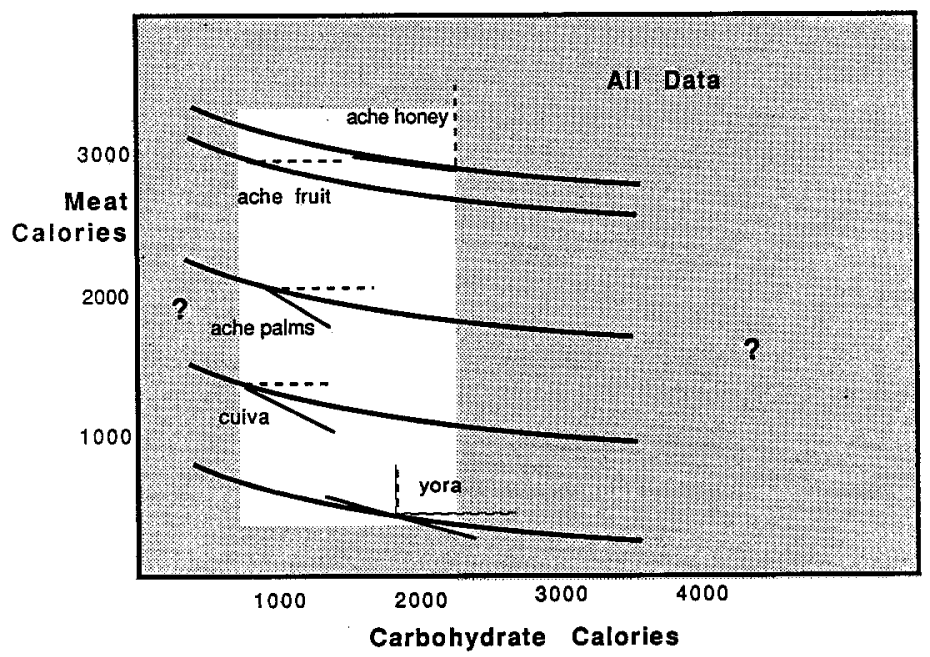

Fig. 13. Using all the restriction angles from Figs. 9-12 to derive an indifference curve for the meat carbohydrate tradeoff. A curve with the same shape can be moved up and down vertically to meet every restriction angle except the left side of the Yora choice point (which is close). The shaded region represents the region for which we have no information. 
Table III. Mbuti Meat/Starch Exchange Rates ${ }^{a}$

\begin{tabular}{|c|c|c|}
\hline & Meat & Starch recieved $(\mathbf{k g})$ \\
\hline & & \\
\hline Exchange & $\begin{array}{l}387 \mathrm{~kg} \times 1460 \mathrm{cal} / \mathrm{k} \\
=565020 \mathrm{cal} \\
\text { te }=1: 4.6\end{array}$ & $\begin{array}{l}262 \mathrm{cal} / \mathrm{kg} \\
\mathrm{cal}\end{array}$ \\
\hline \multicolumn{3}{|c|}{$\begin{array}{l}\text { Observed diet }{ }^{b} \\
\text { Meat: } .375 \mathrm{~kg} / .375 \mathrm{~kg} / \text { consumer day } \times 1460 \mathrm{cal} / \mathrm{kg}=548 \mathrm{cal} \\
\text { Rice: } .060 \mathrm{~kg} / \mathrm{consumer} \text { day } \times 3600 \mathrm{cal} / \mathrm{kg}=216 \mathrm{cal} \\
\text { Cassava flour: } .330 \mathrm{~kg} / \text { consumer day } \times 3200 \mathrm{cal} / \mathrm{kg}=1056 \mathrm{cal}\end{array}$} \\
\hline
\end{tabular}

${ }^{a}$ From Hart (1978, Table VIII).

${ }^{b} N=26$ days (from Hart, 1978, p. 340).

\section{PREDICTION FROM THE DERIVED INDIFFERENCE CURVE: A TEST CASE}

In order to test the utility of the indifference curve that has been tentatively derived above from South American forager data, it is necessary to find another group of human foragers for which the return rates of alternative meat and carbohydrate acquisition activities are known, as well as the diet mix choice point that is achieved by those foragers. Although the necessary data are available for very few foragers, a study of the Mbuti pygmies by Hart (1978) provides all the necessary information. In the situation that Hart describes, the Mbuti begin by acquiring only meat through net hunting (both men and women participate), and then the Mbuti trade some of the meat for manioc flour and rice at a known (and measured) exchange rate. In this case, the female food contribution does not have to be taken as a given, since both sexes cooperate in net hunting. Because any amount of meat can be exchanged for carbohydrate, the choice made between the two resources clearly implies a straight line budget constrain and offers the possibility of any dietary combination ranging from $100 \%$ meat to $100 \%$ carbohydrate.

Mbuti budget constraint and diet choice point calculations are shown in Table III. Hart measured the exchange rate of meat to carbohydrate for 71 exchanges, and the observed exchange rate is 1 calorie of meat traded for 4.6 calories of carbohydrate received. This defines the slope of the budget constraint. The observed diet during the same period (achieved only through net hunting and meat exchange) was 548 calories daily per capita of meat, and 1272 calories per day of carbohydrate. Although the Mbuti could have eaten $100 \%$ meat if protein maximization were the goal, or $100 \%$ carbohydrate if energy maximization were the goal, instead they opted to exchange some of their meat in order to achieve a diet of about $30 \%$ meat and about 


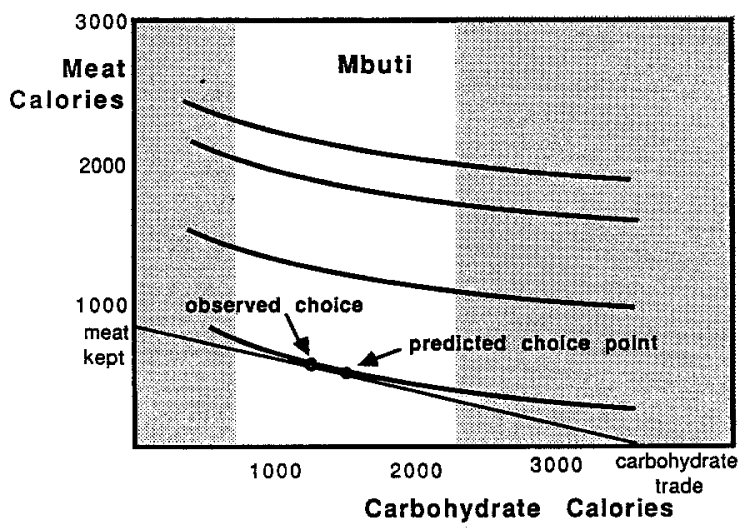

Fig. 14. Using the indifference curve derived in Fig. 12 in order to predict Mbuti diet.

$70 \%$ carbohydrate. Figure 14 shows that the composite indifference curve (from Fig. 13) derived from all the South American data would have predicted a diet of about 490 calories of meat and 1500 calories of carbohydrate for the Mbuti (about $25 \%$ meat and $75 \%$ carbohydrate).

It is interesting that the Mbuti data gree more closely with the implied restriction angle of the Ache meat/fruit tradeoff than with the Yora meat/plantain tradeoff. A single indifference curve slope will meet the restrictions implied by the observed mix for the Mbuti and also meets all other choice points above, except the Yora. On the other hand, using the indifference curve implied by the Yora decision, the Mbuti should eat a diet consisting of $17 \%$ meat and $83 \%$ carbohydrate. This is a serious discrepancy in the predicted and observed carbohydrate component of the diet, and points out how sensitive the choice point will be to shape of the indifference curve and budget constraint slope if both have shallow slopes.

\section{DISCUSSION}

The indifference curve approach to predicting diet is essentially an inductive exercise. It consists of determining preferences from one set of observations (assumed to reflect preferences), then predicting expected diet in a different set of circumstances, by assuming that the derived preference curve is generally applicable. This approach has been called reverse optimality, and has been criticized as doing nothing more than redescribing the data (Maynard Smith, 1978). While this may be true, it is presently unclear how else to proceed if we wish to simply predict how men should forage and whether 
they will concentrate completely on hunting, gathering, or some mix of the two strategies. Of course, in order to truly explain rather than just predict the observed preferences (and thus the foraging patterns), it will be necessary to determine why those preferences exist. From an evolutionary perspective, this means establishing the relationship between fitness and diet across a variety of ecological circumstances.

Given that nutrient modifications of foraging models may be necessary, one can consider whether other approaches exist that might be more productive. Nutrient modifications of foraging decision models to date can generally be classified into two types, complementarity (presented here) and linear programming constraint models. Linear programming models assume that nutrient requirements act to constrain the possible combination of viable foraging strategies such that certain specified minimum amounts of important nutrients must be obtained. If those requirements are not met, the organism will die, but if the requirements are met, further increases in the amount of nutrient consumed will have no further beneficial consequences. In most linear programing models, the rate of intake of a single nutrient, e.g., energy or protein, is assumed to be maximized, subject to meeting the specified nutrient constraints (Reidhead, 1979). When the intake rate maximizing strategy for two resources leads to mutually exclusive optimal foraging strategies, the optimal mix must be determined by some other specified nutrient or non-nutrient constraint (for an example where the constraint that determines the optimal mix of energy and protein is stomach volume see Belovsky, 1987).

Linear programming constraints models may be criticized on both theoretical and empirical grounds. First, the models assume no overlap in search time for various resources. Thus, foragers can hypothetically concentrate on an single resource to the total exclusion of others. This leads to a diet breadth solution in which the number of resource types exploited can never be greater than the number of constraints in the model. The model does not envision the possibility that some resources are encountered while searching for others. Thus, for example, the Ache diet which we observed to include 27 different resources in 1981-1982, could only be explained with at least 26 constraints in addition to one rate-maximizing goal. Second, the assumed step function relationship between consumption and nutritional benefit for constraint nutrients implies either that more nutrients cannot be converted into more viable offspring, that producing more viable offspring is not a goal of foraging organisms, or that the relationship between offspring viability and nutrient quantity is determined by one limiting nutrient in a resource type. Finally, the approach, as it has been applied thus far, has been post hoc. Since subsistence patterns show neither energy nor pro- 
tein maximization, multiple constraints are added to the model one at a time until a close fit to the observed foraging pattern is obtained (Belovsky, 1987). Since the number of possible constraints is unlimited, and constraints and their values are invoked on a case-specific basis, not surprisingly, a specific model can be developed to account for every possible observed diet. While a more general model may eventually be developed, it is presently lacking.

Empirical support for the assumptions of the constraints model is also lacking. Despite years of research, nutrition scientists are unable to agree on the minimum nutritional requirements for human beings (Durnin et al., 1973), and some populations continue to survive and grow while consuming less than the recommended daily minimums used as constraints in the models. This suggests that a simple step function between amount consumed and nutritional benefit may not exit for most nutrients. Experimental evidence cited in the previous section also suggests that intake of macronutrients can be beneficial well above recommended daily minimums. Under food-limiting conditions, which probably apply to most foragers, traditional horticulturalists, and peasants, more food is almot always associated with higher growth rates, offspring survivorship, and general health (Martorell and Habicht, 1986; Zerfas, Jellife, and Jellife, 1986). Access to more food in the Ache society appears to correlate with higher fitness for both males (Kaplan and Hill, 1985b) and females (Hill and Kaplan, 1987b). Comparative data on amount of meat in the diet of many human groups (Chagnon and Hames, 1979; Gross, 1982) also suggest that no specific level of protein in the diet is a human goal unless that goal is many times higher than currently recognized minimum daily requirements. Affluent members of modern societies have considerably higher levels of protein and lipid in their diets than do members of lower economic classes (Willet, 1973). In addition, it is not clear that many of the micronutrients built into complex linear programming models need be incorporated at all. Medium and high levels of general food intake in many circumstances seem to automatically correlate with high levels of intake of a variety of micronutrients (Sanjur and Romero, 1972).

Finally, a consideration of the dietary data presented in this paper clearly illustrates the difficulty with linear programing approaches. The Ache consume a yearly mean of about 2000 calories daily per capita of meat and about 1700 calories daily of carbohydrate (Hill et al., 1984). The Mbuti in Hart's (1978) study consumed about 550 calories per day of meat and 1270 calories per day of carbohydrate. Given the acquisition efficiencies for both groups, a linear programming model of energy maximization would predict a diet of carbohydrate only, and protein maximization would lead to a diet of pure meat for both groups. Energy maximization with a protein constraint would lead to approximately the same diet for both groups (both meeting required minimal protein intake)! 
Despite these difficulties, the logic behind the constraints approach may be somewhat useful for modeling some modifications of foraging behavior that consider specific rare micronutrients which are crucial to survival, e.g., sodium and other minerals. However, considerable evidence suggests that the linear constraint model assumptions are not useful for predicting the optimal mix of macronutrients in the diet and the strategies that should be pursued to acquire that mix. Models based on rate maximization of all macronutrients simultaneously, weighted by their biological value, are likely to be more productive for explaining diet.

The nutrient complementarity model and the protein-lipid/carbohydrate indifference curve derived have important implications for understanding human foraging decisions. First, because meat and vegetable are not equivalently preferred calorie for calorie, and because the preference ratio changes as a function of amount, the first two predictions from the optimal diet model (that resources are always taken or never taken upon encounter, and that resources are added or dropped from the optimal diet according to their energy profitability rank) are unlikely to be upheld in any empirical test where choices available include different classes of resources. Instead, a resource type may be taken until a large quantity is available, and then ignored as the nutritional benefits expected relative to that other resource types decreases. Similarly, some resources may be ignored until a large amount of another resource is available, at which point their relative value may increase and they will be taken.

As complicated as this sounds, a model to predict foraging behavior may not need to take into account the time sequence of decisions. If foragers are knowledgeable about likely and possible acquisition levels at the start of the foraging period, they may simply choose the preferred diet mix from the outset, and then forage in such a way as to meet that goal. They might of course modify their goal if foraging success were substantially different from that expected. As in the case of the optimal diet model, if foods were ranked, only the highest ranking resources of each type (protein-lipid or carbohydrate) should be exploited upon encounter, but the exact diet breadth would be determined by calculating how many higher-ranked resources of each type, when taken upon encounter, would lead to the optimal diet mix. Simply put, foragers should maximize protein-lipid acquisition rates when foraging for that resource class, and they should maximize energy acquisition rates when foraging for carbohydrate resources. The indifference curve is used only to tell them how much of each resource type is optimal during a foraging period.

If this reasoning is correct, when the foraging pattern to be modeled includes only decisions about alternative resources of the same type, e.g., meat, simple optimal foraging modles are likely to be quite successful. Thus, 
for example, the accuracy of predictions concerning men's hunting patterns (Hill and Hawkes, 1982) should be considerably higher than predictions concerning men's total foraging pattern. Similarly, if we take as a given that women will only acquire carbohydrate resources, simple OFT models should be useful for predicting which reources or patches they should exploit. The utility of OFT models for predicting the foraging patterns of nonhuman animals who specialize on a limited set of nutritionally similar resources, e.g., seeds, insects, etc., is also expected to be high.

Several potential problems with the indifference curves approach should also be mentioned. First, the use of human data on resource acquisition to to derive a curve that describes food preferences ignores the steps between acquisition and consumption. The approach assumes, for example, that men will acquire foods in the same amounts that members in the population would prefer to consume them. Since foods are likely to be distributed differentially to members of different age and sex categories in a population, we should consider carefully whether the factors motivating men's foraging are likely to produce the optimal diet mix. If, for example, consumption of high carbohydrate were favorable, yet men received higher fitness payoffs from providing meat (Hawkes, 1987), we might observe a dietary outcome that did not reflect the average preferences of the population.

Second, indifference vurves are likely to be most useful for predicting foraging patterns if they do not change radically as a function of specific population and environmental characteristics. For example, if a very different indifference curve set characterizes populations with high growth rates, male-biased sex ratios, or a large percentage of aged persons, relative to populations with other age-sex characteristics, the generality of the model will be limited. Similarly, if the indifference curve set varies a good deal as a function of local environmental variables, e.g., temperature, rainfall, infectious diseases, parasites, etc., the approach may be unduly complicated. Experimental evidence from rats suggests that self-selected diets do vary somewhat as a function of some of these parameters (Blundell, 1983; p. 176; Leshner et al., 1971).

Other problems have to do with the characteristics of the curves themselves regardless of their generality. First, if the slope of the indifference curve changes greatly as a function of income level, it may be difficult to project the set of curve shapes without considerable data. Data available suggest that the protein-lipid/carbohydrate curve for humans becomes even flatter (favoring protein-lipid) as the income level increases. People in modern societies consume more protein and lipid even though the slope of the budget constraint line is the same for all individuals who shop at the same stores. Since the budget slope is the same, but the diet choice point is different, the indifference curves must also be different such that higher utility indiffer- 
ence curves are flatter (have a shallower negative slope) than lower utility curves. The disagreement between the Ache meat/fruit and Yora meat/plantain restriction angles also suggests that with lower amounts of food available carbohydrate becomes more important relative to meat than is the case with greater food abundance.

Another problem for the utility of the model concerns the slope of the apparent protein-lipid/carbohydrate indifference curve (Bruce Winterhalder first pointed this out). Because the curve derived from South American data is so shallow, and does not show any sharply bending areas, small changes in the budget slope can produce large changes in the predicted carbohydrate component of the diet. Similarly, slight changes in the estimated shape of the indifference curve will strongly effect the predicted diet. This is quite problematic because neither the indifference curve or the budget slope are ever likely to be determined with precision in the field. The sensitivity of predicted outcomes to these parameters is clear in the Mbuti case described above. Consider another example of this problem. Ache men almost never take fruit when the meat/fruit budget slope is about $-1 / 4.8$, but always take honey when the budget slope is about $-1 / 22$. How can we predict whether they will exploit a new vegetable resource characterized by an intermediate budget slope if the model is so sensitive to errors in the shape of the indifference curve or the budget slope? These problems should be further explored. Perhaps the indifference curves approach will only be useful for modeling some types of decisions and not others, or perhaps a further modification to this approach will solve the problem.

Regardless of the shape of the final solution, the nutrients problem is crucial to our understanding of human subsistence patterns, and may be an important key in the sexual division of labor and social organization of foragers. Predicting the mix of food acquisition strategies and diet in subsistence hunter-farmers poses a similar problem. Finally, an understanding of the meat/carbohydrate tradeoff will be necessary in order to evaluate different scenarios proposed for various stages of hominid evolution. Since modern foragers eat more meat than any other large primate, one of the most important questions will be whether the biological vlaue of different macronutrient combinations (shape of the indifference curves) changed through time, or the slope of the budget constraint line (different foraging abilities or technology) changed, or whether some other factor changed to produce a new diet that favored higher meat content.

The empirical evidence presented here suggests several things about human foraging patterns. First, neither energy or protein rate maximization alone accurately predicts forager behavior. Second, foragers do not appear to seek only minimal requirements of any macronutrient. Third, different foraging groups achieve very different mixes of macronutrients despite the 
fact that they could all consume approximately the same ratios of macronutrients. Finally, different groups show large differences in per capita daily total food intake.

We may not yet have discovered an adquate method for answering the questions raised by these observations, but we must develop one. We must also acquire more data to determine whether other forager populations employ subsistence strategies which fail to maximize the energy acquisition rate. Finally, we should carefully consider whether factors other than food nutrients can explain these observations. The ultimate goal is to develop a model that can predict and explain the foraging patterns for different groups of Homo sapiens across time and space. The value of the indifference curve approach can only be determined with more field data, and with further explorations into the types of foraging decisions for which it is appropriate.

\section{ACKNOWLEDGMENTS}

Parts of this research were supported by NSF grants \#BNS-8309834 and \#BNS-8519671, NIH grant \#1 HD16221-01A2, and grants from the L.S.B. Leakey Foundation, National Geographic Society, and Asociacion para la Conservacion de la Selva Sur. K. Hawkes, H. Kaplan, B. Winterhalder, and C. Worthman provided valuable comments. I would also like to thank D. Stephens and $\mathbf{H}$. Horn for directing me to important readings on the use of indifference curves. I apologize to three reviewers whose valuable comments were not incorporated because the initial manuscript was sent directly to press.

\section{REFERENCES}

Altman, S., and Wagner, S. (1978). A general model of optimal diet. In Chivers, D. J., and herbert, J. (eds.), Recent Advances in Primatology (Vol. 1). Academic Press, London, pp. 407-414.

Beckerman, S. (1983). Carpe diem: An optimal foraging approach to Bari fishing and hunting. In Hames, R., and Vickers, W. (eds.), Adaptive Responses of Native Amazonias. New York, Academic Press.

Belovsky, G. E. (1978). Diet optimization in a generalist herbivore, the moose. Theoretical Population Biology 14: 105-134.

Belovsky, G. E. (1984). Herbivore optimal foraging: A comparative test of three models. American Naturalist 124: 97-115.

Belovsky, G. E. (1987). Hunter-gatherer foraging: A linear programing approach. Journal of Anthropology and Archeology 6: 29-76.

Blundell, J. E. (1983). Problems and processes underlying the control of food selection and nutrient intake. In Wurtman, R. J., and Wurtman, J. J. (eds.), Nutrition and the Brain (Vol. 6). New York, Raven Press, pp. 163-221.

Boyd, R., and Richerson, P. (1985). Culture and the Evolutionary Process. University of Chicago Press, Chicago. 
Burkhardt, S., Mercer, L. P. Schweisthal, M., and Cole, T. (1982). Kinetics of specific food intake and weight gain in rats. American Journal of Phisiology 243: 531-536.

Castonguay, T., Hartman, W., Fitzpatrick, E., and Stern, J. (1982). Dietary self-selection and the Zucker Rat. Journal of Nutrition 112: 796-800.

Chagnon, N., and Hames, R. (1979). Protein deficiency and tribal warfare in Amazonia: New data. Science 20: 910-913.

Charnov, E. L. (1973). Optimal Foraging: Some Theoretical Expectations. Unpublished Ph.D. thesis, University of Washington, Seattle, Washington.

Charnov, E. L., and Orians, G. H. (1973). Optimal Foraging: Some Theoretical Explorations. Masters thesis, Department of Biology, University of Utah.

Covich, A. (1972). Ecological economics of seed consumption by peromyscus: A graphical model of resource substitution. Transactions of the Connecticut Academy of the Arts and Sciences 44: 71-93.

Donald, P., Pitts, G., and Pohl, S. (1980). Body weight and composition in laboratory rats: Effects of diets with high or low protein concentration. Science 211: 185-186.

Durnin, J. V. G. A., Edholm, O. G., Miller, D. S., and Waterlow, J, C. (1973). How much food does man require? Nature 242: 418.

Emlen, J. M. (1966). The role of time and energy in food preference. American Naturalist 100 : $611-617$.

Evvard, J. (1915). Proceedings of the Iowa Academy of Science 22: 375-403.

Fomon, S., Thomas, L., Filer, L., Zediler, E., and Leonard, M. (1971). Food consumption and growth of normal infants fed milk-based formulas. Acta paediatr. Scan. (suppl.) 223: 1 .

Gross, D. (1982). Proteina y cultura en al Amazonia: Una segunda revision. Amazonia Peruana 3: 85-97.

Hames, R., and Vickers, W. (1982). Optimal diet breadth theory as a model to explain variability in Amazonian hunting. American Ethnologist 9: 258-278.

Hart, J. (1978). From subsistence to market: A case study of the Mbuti net hunters. Human Ecology 6: 325-353.

Hawkes, K. (1987). Fitness and foraging effort. In Harris, M., and Ross, E. (eds.), Food Preferences and Aversions. Temple University Press, Philadelphia.

Hawkes, K., and O'Connell, J. (1985). Optimal foraging models and the case of the Kung. American Anthropologist 87(2): 401-405.

Hawkes, K., Hill, K., O'Connell, J. (1982). Why hunters gather: Optimal foraging and the Ache of Eastern Paraguay. American Ethnologist 9: 379-398.

Hawkes, K., O'Connell, J., Hill, K., and Charnov, E. (1985). How much is enough? Hunters and limited needs. Ethology and Sociobiology 6: 3-15.

Hickson, J., Wolinsky, I., Pivarnik, J., Neuman, E., Itak, J., and Stockton, J. (1987). Nutritional profile of football athletes eating from a training table. Nutrition Research 7: 27-34.

Hill, K., and Hawkes, K. (1983). Neotropical hunting among the Ache of eastern paraguay. In Hames, R., and Vickers, W. (eds.), Adaptive Responses of Native Amazonians.

Hill, K., and Kaplan, H. (1988). Population Description and Dry Season Subsistence Strategies among the Newly Contacted Yora (Yaminahua) of Manu National Park, Peru. In press National Geographic Research 5(3).

Hill, K., and Kaplan, H. (1987). Tradeoffs in male and female reproductive strategies among the Ache: Part 2. In Betzig, L., Borgerhoff-Mulder, M., and Turke, P. (eds.) Human Reproductive Effort. Cambridge University Press, Cambridge, England.

Hill, K., Hawkes, K., Hurtado, A. M., and Kaplan, H. (1984). Seasonal variance in the diet of Ache hunter-gatherers of eastern Paraguay. Human Ecology 12: 145-180.

Hill, K., Kaplan, H., Hawkes, K, and Hurtado, A. M. (1987). Foraging decisions among Ache hunter-gatherers: New data and implications for optimal foraging models. Ethology and Sociobiology 8: 1-36.

Hurtado, A. M. (1985). Womens Subsistence Strategies among Ache Hunter-Gatherers of Eastern Paraguay. Unpublished Ph.D. thesis, University of Utah.

Hurtado, A. M., and Hill, K. (1986). The Cuiva: Hunter-gatherers of Western Venezuela. Anthroquest 36. 
Hurtado, A. M., and Hill, K. (1987). Early dry season subsistence ecology of Cuiva foragers of Venezuela. Human Ecology 15(2).

Hurtado, A. M., Hawkes, K., and Hill, K. (1985). Female subssitence strategies among the Ache of eastern Paraguay. Human Ecology 13: 1-28.

Jerome, N., Pelto, G., and Kandel, R. (1980). An ecological approach to nutritional anthropology. In Jerome, N., Kandel, R., and Pelto, G. (eds.), Nutritional Anthropology. Redgrave, New York.

Kaplan, H. (1983). The Evolution of Food Sharing among Adult Conspecifics: Research with the Ache Foragers of Paraguay. Unpublished Ph.D. thesis, University of Utah.

Kaplan, H., and Hill, K., (1985a). Food sharing among Ache foragers: Tests of explanatory hypothesis. Current Anthropology 26(2): 223-246.

Kaplan, H., and Hill, K. (1985b). Hunting ability and reproductive success among male Ache foragers: Preliminary results. Current Anthropology 26(1): 131-133.

Keene, A. (1981). Optimal foraging in a non-marginal environment: A model of prehistoric subsistence strategies in Michigan. In Winterhalder, B., and Smith, E. A. (eds.), HunterGatherer Foraging Strategies. University of Chicago Press, Chicago.

Leshner, A., Collier, G., and Squibb, R. (1971). Physiology and Behavior 6: 1-3.

Leung, W. T. (1961). Food Composition Table for use in Latin America, NIH, Bethesda, Md.

MacArthur, R. H., and Pianka, E. R. (1966). On optimal use of a patchy environment. American Naturalist 100: 603-609.

Martorell, R., land Habicht, J.-P. (1986). Growth in early childhood in developing countries. In Falkner, F., and Tanner, J. (eds.), Human Growth: A Comprehensive Treatise (Vol. 3). Plenum Press, New York.

Maynard Smith, J. (1978). Optimization theory in evolution. Am. Rev. Ecol. Syst. 9: 31-56.

Miller, D., and Mumford, P. (1967). An experimental study of overeating low or high protein diets. American Journal of Clinical Nutrition 20: 1212-1222.

Milton, K. (1979). Factors influencing leaf choice by Howler Monkeys. A test of some hypotheses of food selection by generalist herbivores. American Naturalist 114: 362-378.

Montgomery, E., and Johnson, A. (1977). Machiguenga energy expenditure. Ecology of Food and Nutrition 6: 97-105.

O'Connell, J., and Hawkes, K. (1981). Alywara plan use and optimal foraging theory. In Winterhalder, B., and Smith, E. A. (eds.), Hunter-Gatherer Foraging Strategies. University of Chicago Press, Chicago.

Pulliam, H. R. (1975). Diet optimization with nutrient constraints. American Naturalist 109: 765-768.

Pyke, G., Pullaim, H. R., and Charnov, E. (1977). Optimal foraging: A selective review of theory and test. Quarterly Review of Biology 52: 137-154.

Rachlin, H., Battalio, R., Kagel, J., and Green, L. (1981). Maximization theory in behavioral psychology. Behavioral Brain Science 4: 371-417.

Rapport, D. J. (1971). An optimization model of food selection. American Naturalist 105: 575-587.

Rapport, D. J. (1980). Optimal foraging for complementary resources. American Naturalist 116: 324-346.

Reidhead, V. A. (1979). Linear programming models in archeology. Annual Review of Anthropology. 79: 543-578.

Sanjur, D., and Romero, E. (1972). Conceptual levels of dietary indicators as predictors of nutritional status. Proceedings of the Ninth International Congress on Nutrition, 2: 214-222.

Sih, A., and Milton, K. (1985). Optimal diet theory: Should the !Kung eat mongongos. American Anthropologist 87(2): 395-400.

Smith, E. A. (1980). Evolutionary Ecology and the Analysis of Human Foraging Behavior. Unpublished Ph.D. thesis, Cornell University.

Smith, E. A. (1981). The application of optimal foraging theory to the analysis of hunter-gatherer group size. In Winterhalder, B., and Smith, E. A. (eds.), Hunter-Gatherer Foraging Strategies. University of Chicago Press, Chicago.

Smith, E. A. (1983). Anthropological applications of optimal foraging theory: A critical review. Current Anthropology 24: 625-651. 
Smith, E. A. (1985). Inuit foraging groups: Some simple models incorporating conflicts of interest, relatedness, and central place sharing. Ethology and Sociobiology 6: 37-57.

Smith, E. A. (1987). Risk and uncertainty in the "original afluent society": Evolutionary ecology of resource sharing and land tenure. In Woodburn, J., Ingold, T., and Riches, D. (eds.), History, Evolution, and Social Change in Hunting and Gathering Societies. Berg Publishers, London.

Stephens, D., and Krebs, J. (1987). Foraging Theory. Princeton University Press, Princeton. Tilman, D. (1982). Resource Competition and Community Structure. Princeton University Press, Princeton.

Willet, J. (1973). Food needs and the effective demand for food. In Poleman and Freebank (eds.), Food, Population and Employment: The Impact of the Green Revolution. Praeger, New York.

Winterhalder, B. E. (1977). Foraging Strategies and Adaptations of the Boreal Forest Cree: An Evaluation of Theory and Models from Evolutionary Ecology. Unpublished Ph.D. thesis, Cornell, University.

Winterhalder, B. E. (1981). Foraging strategies in the Boreal environment: An analyses of Cree hunting and gathering. In Winterhalder, B., and Smith, E. A. (eds.), Hunger-Gatherer Foraging Strategies: Ethnographic and Acheological Analyses. University of Chicago Press, Chicago.

Winterhalder, B. (1983). Opportunity-cost foraging models for stationary and mobile predators. American Naturalist 122: 73-84.

Winterhalder, B. E. (1987). Diet choice, risk, and food sharing in a stochastic environment. Journal of Anthropological Archeology 5: 369-392.

Winterhalder B., and Smith, E. A. (1981). Hunter-Gatherer Foraging Strategies: Ethnographic and Acheological Analyses. University of Chicago Press, Chicago.

Yoshimura, Y., Kighi, K., Matsumot, Y., and Inoue, S. (1982). Quantitative effects of nitrogen and energy intakes on body weight and nitrogen retention in adult rats. Tokushima Journal of Exp. Medicine 29: 163-172.

Zefas, A., Jellife, D., and Jellife, E. F. P. (1986). Epidemiology and nutrition. In Falkner, F., and Tanner, J. (eds.), Human Growth: A Comprehensive Treatise (Vol. 3). Plenum Press, New York. 